\title{
The Zugspitze radiative closure experiment for quantifying water vapor absorption over the terrestrial and solar infrared - Part 1: Setup, uncertainty analysis, and assessment of far-infrared water vapor continuum
}

\author{
Ralf Sussmann, Andreas Reichert, and Markus Rettinger \\ Karlsruhe Institute of Technology, IMK-IFU, Garmisch-Partenkirchen, Germany \\ Correspondence to: Ralf Sussmann (ralf.sussmann@kit.edu)
}

Received: 13 April 2016 - Published in Atmos. Chem. Phys. Discuss.: 25 April 2016

Revised: 30 August 2016 - Accepted: 2 September 2016 - Published: 21 September 2016

\begin{abstract}
Quantitative knowledge of water vapor radiative processes in the atmosphere throughout the terrestrial and solar infrared spectrum is still incomplete even though this is crucial input to the radiation codes forming the core of both remote sensing methods and climate simulations. Beside laboratory spectroscopy, ground-based remote sensing field studies in the context of so-called radiative closure experiments are a powerful approach because this is the only way to quantify water absorption under cold atmospheric conditions. For this purpose, we have set up at the Zugspitze $\left(47.42^{\circ} \mathrm{N}, 10.98^{\circ} \mathrm{E} ; 2964 \mathrm{~m}\right.$ a.s.1.) a long-term radiative closure experiment designed to cover the infrared spectrum between 400 and $7800 \mathrm{~cm}^{-1}(1.28-25 \mu \mathrm{m})$. As a benefit for such experiments, the atmospheric states at the Zugspitze frequently comprise very low integrated water vapor (IWV; minimum $=0.1 \mathrm{~mm}$, median $=2.3 \mathrm{~mm}$ ) and very low aerosol optical depth $\left(\mathrm{AOD}=0.0024-0.0032\right.$ at $7800 \mathrm{~cm}^{-1}$ at air mass 1). All instruments for radiance measurements and atmospheric-state measurements are described along with their measurement uncertainties. Based on all parameter uncertainties and the corresponding radiance Jacobians, a systematic residual radiance uncertainty budget has been set up to characterize the sensitivity of the radiative closure over the whole infrared spectral range. The dominant uncertainty contribution in the spectral windows used for far-infrared (FIR) continuum quantification is from IWV uncertainties, while $T$ profile uncertainties dominate in the mid-infrared (MIR). Uncertainty contributions to near-infrared (NIR) radiance residuals are dominated by water vapor line parameters in the vicinity of the strong water vapor bands. The
\end{abstract}

window regions in between these bands are dominated by solar Fourier transform infrared (FTIR) calibration uncertainties at low NIR wavenumbers, while uncertainties due to AOD become an increasing and dominant contribution towards higher NIR wavenumbers. Exceptions are methane or nitrous oxide bands in the NIR, where the associated line parameter uncertainties dominate the overall uncertainty.

As a first demonstration of the Zugspitze closure experiment, a water vapor continuum quantification in the FIR spectral region $\left(400-580 \mathrm{~cm}^{-1}\right)$ has been performed. The resulting FIR foreign-continuum coefficients are consistent with the MT_CKD 2.5.2 continuum model and also agree with the most recent atmospheric closure study carried out in Antarctica. Results from the first determination of the NIR water vapor continuum in a field experiment are detailed in a companion paper (Reichert and Sussmann, 2016) while a novel NIR calibration scheme for the underlying FTIR measurements of incoming solar radiance is presented in another companion paper (Reichert et al., 2016).

\section{Introduction}

Water vapor causes about $60 \%$ of the telluric greenhouse effect and about $72 \%$ of the atmospheric absorption of incoming solar radiation for clear skies (Kiehl and Trenberth, 1997). Furthermore, water vapor feedback approximately doubles the response of surface temperature to the imposition of an external forcing, e.g., anthropogenic $\mathrm{CO}_{2}$ emis- 
sions (Held and Soden, 2000). Finally, water vapor is a target species for spectrometric remote sensing methods based on the differential optical absorption principle, and, due to its high variability, it is also a potential interfering species for remote sensing of all other atmospheric trace gases (Frankenberg et al., 2008; Sussmann and Borsdorff, 2007; Sussmann et al., 2011). All in all, it is important to put efforts toward a quantitative understanding of all details of water vapor absorption throughout the whole terrestrial and solar infrared spectrum.

Numerical approaches dedicated to weather forecast, climate prediction, and remote sensing data analysis are based upon radiative transfer codes calculating the absorption and/or emission of radiation by atmospheric trace gases, aerosols, and clouds as a function of wavelength. Modeling the radiative impact of the gas phase molecular compounds has to include radiative processes such as pure rotational absorption/emission in the far infrared (FIR) and vibrationrotation absorption/emission in the mid-infrared (MIR) and the near infrared (NIR). According to quantum mechanical selection rules, both processes lead to atmospheric bandtype absorption/emission spectra with thousands of individual spectral lines. The most accurate (but time-consuming) way of simulating these processes is a fully resolved line-byline approach, e.g., via the widely used Line-By-Line Radiative Transfer Model (LBLRTM; Clough et al., 2005; Mlawer et al., 2012). The LBLRTM is then used as validation reference for the faster rapid radiative transfer model (RRTM), which avoids time-consuming line-by-line calculations by a correlated- $k$ approach (Mlawer et al., 1997) and is used within many climate models (i.e., general circulation models).

However, there are still uncertainties which potentially introduce biases into the applications (climate simulations, weather forecast, remote sensing). One class of uncertainties is related to the spectroscopic line parameters (e.g., line strength and pressure-broadened half width). For example, the current spectroscopic foundation of LBLRTM is the line parameters database aer_v_3.2, which is built from HITRAN (HIgh-resolution TRANsmission molecular absorption database) 2008 (Rothman et al., 2009) with notable exceptions for $\mathrm{H}_{2} \mathrm{O}, \mathrm{CO}_{2}, \mathrm{CH}_{4}$, and $\mathrm{O}_{2}$ (for details see http://rtweb.aer.com/line_param_whats_new.html). Another source of uncertainty is the so-called continuum absorption, especially due to water vapor. It is a spectrally less structured contribution dominating in window regions (e.g., Shine et al., 2012) which comprises two components: the self-continuum (attributed to $\mathrm{H}_{2} \mathrm{O}-\mathrm{H}_{2} \mathrm{O}$ interactions) and the foreign continuum (attributed to $\mathrm{H}_{2} \mathrm{O}$-air interactions). Although a definite continuum theory still does not exist, it seems that a consensus has been reached on the existence of the two possible physical processes contributing, namely (i) monomer contributions resulting from perturbations of the line shape due to (self- and foreign) pair interactions during molecular collisions and (ii) dimer contribu- tions, i.e., absorption due to stable and/or metastable dimers. Evidence for the existence of water dimers in the atmosphere has been reported by Pfeilsticker et al. (2003) and Ptashnik (2008). However, the relative importance of the monomer and dimer contributions as a function of temperature and wavenumber (especially for window vs. in-band regions) are far from being understood. For recent reviews, see Shine et al. (2012), Mlawer et al. (2012), and references therein. The most widely used water vapor continuum model at this time (MT_CKD 2.5.2) is based on the monomer hypothesis, while contributions from water dimers shall be implemented in future versions (Mlawer et al., 2012). MT_CKD is a semiempirical model combining a line shape component and a weak interaction component. In both terms empirical parameters are set in a way to achieve agreement with laboratory and field measurements. Constraining measurements have hitherto been restricted to measurements within the microwave, the FIR, the MIR, and, recently, also the NIR; see Mlawer et al. (2012) for details and references. This means that considerable fractions of the full 0-20000 $\mathrm{cm}^{-1}$ range of MT_CKD are semiempirical extrapolations in between the constraining measurements; i.e., the continuum parameters reported there are more uncertain.

The potential impact of line parameter or continuum model uncertainties has been investigated in a series of papers. For example, one study investigated the impact of improved NIR water vapor line parameters in simulations with the ECHAM4 general circulation model (Lohmann and Bennartz, 2002). They found that the global annual mean atmospheric absorption of solar radiation in the atmospheric general circulation model ECHAM4 is increased under all skies between 3.2 and $3.7 \mathrm{~W} \mathrm{~m}^{-2}$ and between 5.0 and $5.7 \mathrm{~W} \mathrm{~m}^{-2}$ under clear skies for the different data sets. While the dynamics barely change, the hydrological cycle is slightly weaker, the cloud cover has decreased by $0.4 \%$ and the precipitation by 0.06 to $0.08 \mathrm{~mm} \mathrm{day}^{-1}$ with the new data set. A FIR continuum study showed that modifications to the previously derived strength of the water vapor continuum in the $10-700 \mathrm{~cm}^{-1}$ region within the Community Earth System Model (CESM) had a statistically significant impact on both the radiation and dynamics with changes in the vertical structure of temperature, humidity, and cloud amount, all of which impacted the diabatic heating profile (Turner et al., 2012a). Paynter and Ramaswamy (2012) showed that the water vapor continuum could result in between 1.1 and $3.2 \mathrm{~W} \mathrm{~m}^{-2}$ additional clear-sky absorption of solar radiation globally. According to Paynter and Ramaswamy (2014), this sizable range is due to fairly large measurement uncertainties in the shortwave near-infrared window regions (Ptashnik et al., 2004, 2011, 2012, 2013; Paynter et al., 2007, 2009; Baranov and Lafferty, 2011, 2012; Mondelain et al., 2013). After the inclusion of a modified parameterization for the shortwave water vapor continuum (BPS-MTCKD 2.0) to the Geophysical Fluid Dynamics Laboratory (GFDL) global model, Paynter and Ramaswamy (2014) found that the surface en- 
ergy budget adjusted predominantly through a decrease in both surface latent and sensible heat. This leads to a decrease in tropical convection and a subsequent $1 \%$ reduction in tropical rainfall. This result is consistent with the finding of DeAngelis et al. (2015) that the treatment of shortwave absorption by water vapor in climate models has a major influence on the response of the hydrological cycle to climate change. Finally, a recent NIR continuum study investigated the impact of switching from the Clough-Kneizys-Davies (CKD) continuum model frequently used in climate models to a continuum model where absorption is enhanced at wavelengths greater than $1 \mu \mathrm{m}$ based on recent measurements of the CAVIAR (Continuum Absorption at Visible and Infrared wavelengths and its Atmospheric Relevance) consortium. They found that for CKD and CAVIAR respectively, and relative to the no-continuum case, the solar component of the water vapor feedback is enhanced by about 4 and $9 \%$, the change in clear-sky downward surface irradiance is 7 and $18 \%$ more negative, and the global-mean precipitation response decreases by 1 and $4 \%$ (Rädel et al., 2015).

Due to the critical relevance of line parameter and continuum model uncertainties for climate simulations, a series of quality measurement experiments has been performed. Such field closure studies comprise high spectral-resolution radiance measurements and radiative transfer simulations of the measured spectra driven by coincident atmospheric-state measurements of integrated water vapor (IWV) and other relevant parameters. As part of the US Atmospheric Radiation Measurement (ARM) program (Ackermann and Stokes, 2003), a series of radiative closure experiments has been set up (e.g., Turner et al., 2004, 2012b) which was complemented by the Italian ECOWAR (Earth COoling by WAter vapor Radiation) project (e.g., Bhawar et al., 2008; Bianchini et al., 2011). Various experiments have addressed the quality of (water vapor) line parameters in the FIR (Esposito et al., 2007; Delamere et al., 2010; Masiello et al., 2012), the water vapor continuum in the FIR (Tobin et al., 1999; Serio et al., 2008; Delamere et al., 2010; Liuzzi et al., 2014), and the water vapor continuum in the MIR (Turner et al., 2004; Rowe et al., 2006; Rowe and Walden, 2009). A crucial requirement for radiative closure experiments in the FIR and MIR is to select a site guaranteeing a wide range of IWV levels including the occurrence of very low IWV levels. Dry atmospheric states (IWV $<1 \mathrm{~mm}$ ) are highly beneficial for attaining information on absorption coefficients in otherwise saturated spectral regions (e.g., the pure rational water band of water vapor). For these reasons, there have been dedicated campaigns performed in dry regions on the globe, e.g., at the SHEBA (Surface HEat Budget of the Arctic ocean) ice station (Tobin et al., 1999) or the RHUBC (Radiative heating in underexplored bands campaign) I and RHUBC II campaigns carried out in Alaska and in the Atacama desert, respectively (Turner and Mlawer, 2010).

Coming to the NIR we note that for this spectral region to our knowledge no atmospheric radiative closure experi- ments have been reported in the literature with the exception of the studies by Sierk et al. (2004) and Mlawer et al. (2014). A hindrance for quantitative field studies may have been the fact that absorption in the NIR due to aerosols can become comparable to the magnitude of the water vapor continuum absorption of interest (Ptashnik et al., 2015). The possibility to accurately separate these two components depends on aerosol load (i.e., aerosol optical depth, AOD) and therefore on field site characteristics, as will be outlined when introducing the new Zugspitze field experiment below. On the other side, there have been many laboratory studies in the NIR range. Laboratory experiments using Fourier transform infrared (FTIR) spectrometry and large cells have shown that the self- and foreign continuum within the windows was found to be significantly stronger than given by MT_CKD (Baranov and Lafferty, 2011; Ptashnik et al., 2011, 2012, 2013). Another issue is that laboratory measurements performed by different techniques have yielded too inconsistent results. For example, the magnitude of the self-continuum in NIR windows derived from laboratory FTIR spectrometry is higher by about 1 order or magnitude compared to results obtained by cavity ring-down spectroscopy (CRDS; Mondelain et al., 2013, 2015), which furthermore differ significantly from laboratory results obtained by calorimetric interferometry (Bicknell et al., 2006). Finally, a drawback of laboratory measurements is that they are typically performed at least at room temperature or even heated, in order to detect the weak continuum absorption in the limited optical path length of the cells. Therefore, for climate and remote sensing applications an extrapolation of continuum coefficients to the lower atmospheric temperatures is required, which may lead to significant inaccuracies due to the uncertainty of the selfcontinuum temperature dependence (e.g., Shine et al., 2012).

Our review of previous activities to advance the quantitative knowledge on water vapor absorption indicates a need for further radiative closure studies in order to (i) validate/complement the previous studies in the FIR and MIR and (ii) establish an NIR closure experiment in the field in order to provide an independent assessment of the existing but differing laboratory results with respect to their mutual agreement and the agreement vs. MT_CKD under atmospheric conditions.

The goal of this paper is therefore to report on a new water vapor radiative closure experiment set up on the summit of the Zugspitze $\left(47.42^{\circ} \mathrm{N}, 10.98^{\circ} \mathrm{E} ; 2964 \mathrm{~m}\right.$ a.s.l.) covering the FIR, MIR, and NIR spectral range. This experiment is not a campaign but designed as a long-term (multi-annual) study with the benefit of attaining improved data statistics compared to campaigns. Furthermore, the Zugspitze is a unique site as it is not remote (accessible by cable car) but at the same time offers extraordinarily dry conditions and low aerosol loads. As outlined before, these are crucial prerequisites for closure studies, and on dry winter days, the Zugspitze regularly offers conditions comparable to the driest sites and sites with the highest atmospheric transparency 
on the globe. The history of the Zugspitze site and team is linked to ground-based solar FTIR remote sensing with some focus on water vapor (e.g., Sussmann et al., 2009; Vogelmann et al., 2011, 2015). The Zugspitze solar FTIR is part of the Network for the Detection of Atmospheric Composition Change (NDACC; http://www.ndacc.org), which also comprises a working group on water vapor sounding techniques (e.g., Kämpfer, 2013). This paper describes an extension of the Zugspitze instrumentation including the NDACC solar FTIR system (Sussmann and Schäfer, 1997) adapted for NIR radiance measurements and complemented by additional instruments for FIR and MIR radiance measurements and IWV sounding as well as further measurements of the atmospheric state.

Our publication on the Zugspitze radiative closure experiment comprises a set of three companion papers, hereafter designated Part 1, 2, and 3. This paper (Part 1) illustrates the basic idea and setup in Sect. 2. Section 3 details the radiance measurements in the FIR, MIR, and NIR, followed by Sect. 4 describing the state measurements, Sect. 5 describing the radiative transfer calculations, and Sect. 6 giving a detailed uncertainty analysis. Finally, Sect. 7 shows an example closure study in the FIR, and the results are compared to MT_CKD and other field measurements. Part 2 is on a novel calibration scheme for solar FTIR radiance measurements, and Part 3 gives the application of this to an NIR closure study, with the results on the NIR water vapor continuum compared to MT_CKD and laboratory measurements.

\section{Idea and setup of the closure experiment}

At the summit of the Zugspitze $\left(47.42^{\circ} \mathrm{N}, 10.98^{\circ} \mathrm{E}\right.$; $2964 \mathrm{~m}$ a.s.l.), we have set up spectral radiance measurements covering the FIR, the MIR, and the NIR along with atmospheric-state measurements, most importantly IWV (Fig. 1 and Table 1). The idea of the closure experiment is to compare measured radiance spectra with simulations of the spectra driven by coincident-state measurements. Minimization of measured minus simulated spectral radiance (hereafter referred to as "spectral residuals") leads to improved water vapor absorption parameters, used in the radiance simulations (Fig. 2). The basic principle behind this approach has been presented before (e.g., Tobin et al., 1999; Turner and Mlawer, 2010). However, there are four aspects which are special to our Zugspitze setup:

i. Very dry atmospheric conditions are a prerequisite for closure studies of this kind due to the otherwise saturated spectral regions (see, e.g., Fig. 1 in Tobin et al., 1999). To achieve this goal previous campaigns were performed at remote locations like the SHEBA ice station (Tobin et al., 1999) or in the Atacama desert where IWV levels down to $0.2 \mathrm{~mm}$ were achieved (Turner and Mlawer, 2010). On the other hand, at the Zugspitze we frequently encounter comparably dry atmospheric

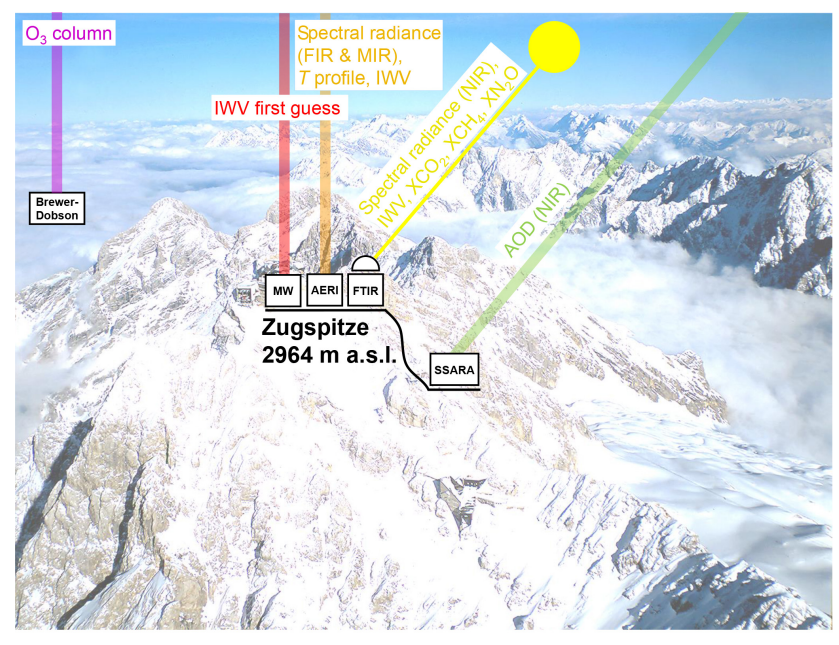

Figure 1. Instrumental setup of the Zugspitze radiative closure experiment covering the FIR, MIR, and NIR spectral range (FTIR: Bruker IFS 125 HR high-resolution solar Fourier transform infrared spectrometer; AERI: extended-range Atmospheric Emitted Radiance Interferometer; MW: LHATPRO (low-humidity and temperature profiling) microwave radiometer; SSARA (Sun-Sky Automatic RAdiometer - Zugspitze): sun photometer; Brewer-Dobson: ozone spectrophotometer).

conditions ( $\min$ IWV $=0.1 \mathrm{~mm}$; see Fig. 3 and Table 2), but the Zugspitze is at the same time an easyto-access site, which can be reached within 20 min by cable car from our institute's building in GarmischPartenkirchen. Note that the minimum IWV levels at the Zugspitze $(0.1 \mathrm{~mm})$ are approximately a factor of 40 lower than at typical lowland midlatitude sites.

ii. Unlike previous campaign-type studies, our field experiment is designed as a long-term study (timescale $\sim 10$ years) - this is beneficial for attaining improved measurement statistics.

ii. The Zugspitze radiative closure experiment is - to our knowledge for the first time - extended to include the NIR spectral range, while previous studies focused on the MIR (e.g., Tobin et al., 1999) and FIR (e.g., Delamere et al., 2010).

iv. A benefit of the Zugspitze high-altitude mountain site is that AOD is typically very low, i.e., about a factor of 10 lower than at typical lowland midlatitude sites. This is important because otherwise in the NIR the AOD would become significantly higher than the water vapor continuum optical depth and this would be a hindrance for accurate continuum quantification in the NIR (Ptashnik et al., 2015). The AOD levels encountered in the Zugspitze closure data set used in this study (i.e., dry clear-sky days within the time span December 2013February 2014; see Sect. 7.1 for data selection details) 
Table 1. Instruments and geophysical parameters measured at the Zugspitze radiative closure experiment. Uncertainties are given for $2 \sigma$ confidence.

\begin{tabular}{|c|c|c|c|}
\hline Geophys. parameter & Instrument & Repeat cycle & Uncertainty/specification \\
\hline $\begin{array}{l}\text { FIR \& MIR spectral radiance } \\
\left(400-3000 \mathrm{~cm}^{-1}\right)\end{array}$ & ER-AERI & $10 \mathrm{~min}$ & $\begin{array}{l}* \text { resolution } 0.5 \mathrm{~cm}^{-1} \\
\text { calibration bias }<0.66 \% \text { of ambient } \mathrm{BB} \text { ra- } \\
\text { diance } \\
\text { calibration precision }<0.13 \% \text { of ambient } \mathrm{BB} \\
\text { radiance }\end{array}$ \\
\hline $\begin{array}{l}\text { NIR spectral radiance } \\
\left(2500-7800 \mathrm{~cm}^{-1}\right)\end{array}$ & solar FTIR & $75-150 \mathrm{~s}$ & $\begin{array}{l}* \text { resolution } 0.011 \mathrm{~cm}^{-1} \\
\text { calibration accuracy } 0.6-1.7 \% \text { of measured } \\
\text { radiance }\end{array}$ \\
\hline IWV (ER-AERI) & $\begin{array}{l}\text { retrieval from ER- } \\
\text { AERI spectra }\end{array}$ & $10 \mathrm{~min}$ & $\begin{array}{l}\text { bias } 2.5 \% \\
\text { precision } 1.9 \%\end{array}$ \\
\hline IWV (solar FTIR) & $\begin{array}{l}\text { retrieval from solar } \\
\text { FTIR spectra }\end{array}$ & $75-150 \mathrm{~s}$ & $\begin{array}{l}\text { bias } 1.1 \% \\
\text { precision } 0.8 \%\end{array}$ \\
\hline Water vapor profile shape & NCEP & $6 \mathrm{~h}$ & $\begin{array}{l}\text { bias } 1.7 \% \\
\text { precision } 9.4 \%\end{array}$ \\
\hline Temperature profile & ER-AERI \& NCEP & $10 \mathrm{~min}$ & accuracy $<1 \mathrm{~K}$ \\
\hline $\mathrm{O}_{3}$ column & Brewer-Dobson & $\sim 30 \mathrm{~min}$ & accuracy $<1 \%$ \\
\hline $\mathrm{XCO}_{2}$ & TCCON & $100 \mathrm{~s}$ & $\begin{array}{l}\text { bias }<0.07 \% \\
\text { precision }<0.25 \%\end{array}$ \\
\hline $\mathrm{XCH}_{4}$ & TCCON & $100 \mathrm{~s}$ & $\begin{array}{l}\text { bias }<1.04 \% \\
\text { precision }<0.3 \%\end{array}$ \\
\hline $\mathrm{XN}_{2} \mathrm{O}$ & TCCON & $100 \mathrm{~s}$ & $\begin{array}{l}\text { bias }<1.85 \% \\
\text { precision }<0.5 \%\end{array}$ \\
\hline NIR AOD & SSARA & $1 \mathrm{~s}$ & $\begin{array}{l}\text { accuracy at air mass } 1 \\
<0.0015\left(\text { at } 2500 \mathrm{~cm}^{-1}\right) \\
<0.0025\left(\text { at } 7800 \mathrm{~cm}^{-1}\right)\end{array}$ \\
\hline
\end{tabular}

* Resolution defined as 1 / maximum optical path difference $\left(\mathrm{OPD}_{\max }\right)$.

Table 2. Climatological statistics of clear-sky IWV levels above the Zugspitze derived from $N$ multi-annual solar FTIR measurements shown in Fig. 3. Numbers are given in units of (mm).

\begin{tabular}{rrrrrr}
\hline$N$ & Mean & SD & Min & Median & Max \\
\hline 7388 & 3.0 & 2.2 & 0.1 & 2.3 & 12.0
\end{tabular}

are in the range of $0.0005-0.00075$ at $2500 \mathrm{~cm}^{-1}$ and in the range of $0.0024-0.0032$ at $7800 \mathrm{~cm}^{-1}$ at air mass 1 .

\section{Spectral radiance measurements}

\subsection{FIR and MIR radiance measurements}

Downwelling thermal emission is measured in the FIR and MIR spectral range from 400 to $3000 \mathrm{~cm}^{-1}(25-3.3 \mu \mathrm{m})$ via an Extended-range Atmospheric Emitted Radiance Interferometer (ER-AERI). This instrument was designed by the University of Wisconsin Space Science and Engineering Centre and is manufactured by ABB Bomem Inc. (Quebec, Canada). Details of the instrument design and performance have been given by Knuteson et al. (2004a, b). AERI or
ER-AERI instruments have, for example, been operated at the SHEBA Ice Station (Tobin et al., 1999), in the Atacama Desert (Turner and Mlawer, 2010), or at Eureka, CA (Mariani et al., 2012). Briefly, the instrument inside the Zugspitze container is based on a $0.5 \mathrm{~cm}^{-1}$ resolution (maximum optical path difference $\left(\mathrm{OPD}_{\max }\right)$ of $\left.1 \mathrm{~cm}\right)$ FTIR spectrometer. The interferometer front window is linked to the front end which is mounted outside the container in the so-called through-wall configuration. It comprises the scene mirror and two calibration blackbodies (BB), which are operated at ambient temperature and at $310 \mathrm{~K}$ (Fig. 2). The front end hatch used to protect the scene mirror from precipitation has been modified from its original flat-roof shape to a pitched-roof shape in order to avoid snow accumulations. Scan duration for one interferogram is $2 \mathrm{~s}$ and the total repeat cycle is $10 \mathrm{~min}$, with $4 \mathrm{~min}$ integration for the atmospheric observations, and $2 \times 2$ min for the blackbody measurements.

Radiometric calibration of the ER-AERI is performed via the approach by Revercomb et al. (1988). The related FIR and MIR radiometric uncertainty specifications are given in Table 1, and more details will be presented in Sect. 6.1. Briefly, there is a known radiometric bias in the ER-AERI radiance measurements which was corrected via the method proposed by Delamere et al. (2010). This method relies on 


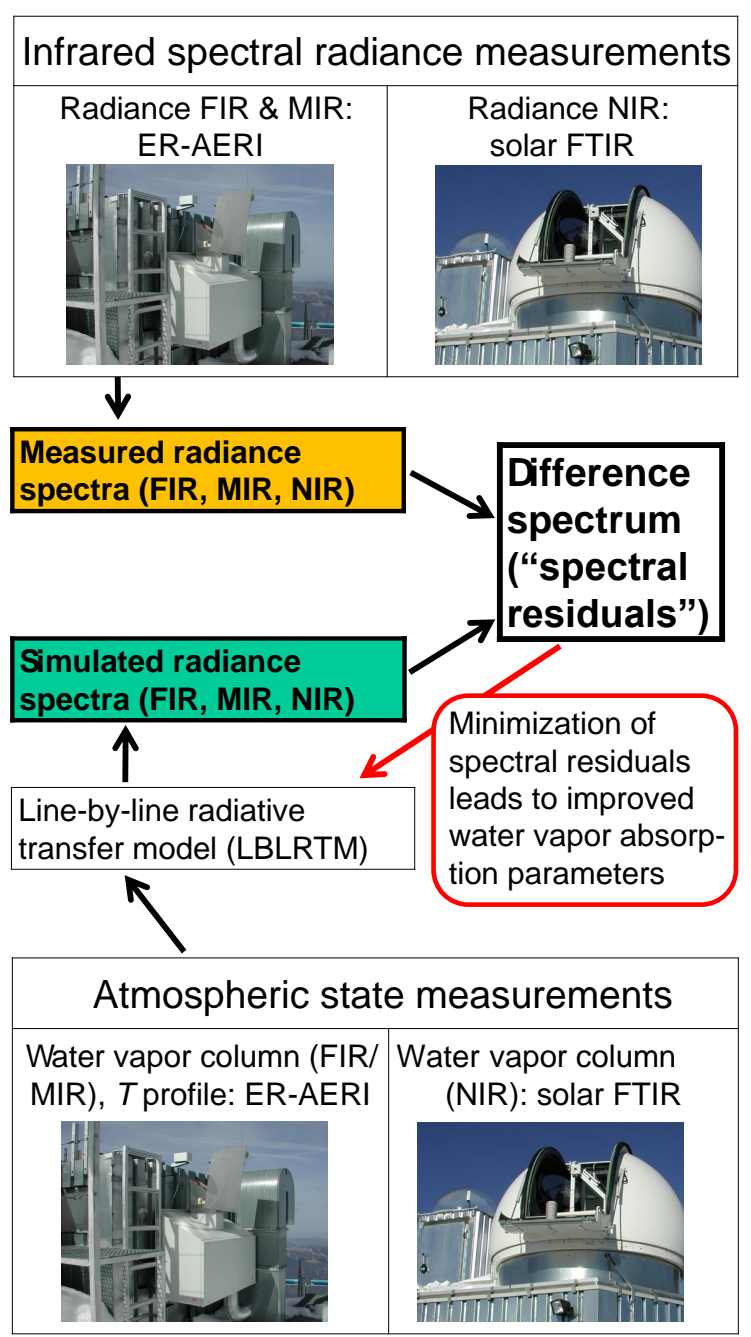

Figure 2. Logical scheme of the Zugspitze radiative closure experiment. Simulated radiance spectra are based on atmospheric-state measurements performed coincidently with the radiance measurements. The closure idea is to minimize spectral residuals between simulated and measured radiance spectra by iteratively adjusting and improving the water vapor absorption parameters used in the FIR, MIR, and NIR spectral radiance simulations.

the assumption that a fraction $f$ of the instrument's field of view is obstructed by instrument parts. The value of $f$ is constrained by a fit to measured radiance in the 827 to $835 \mathrm{~cm}^{-1}$ spectral window. We obtain $f=0.0049$, which is then used for performing the bias correction according to Delamere et al. (2010).

An estimate of radiance measurement noise of the ERAERI is obtained as an output from the calibration procedure (see Sect. 6.1). The spectral radiance noise can be reduced using a filter based on principal component analysis as outlined in Antonelli et al. (2004) and Turner et al. (2006). Based on 8000 Zugspitze spectra, this analysis indicated that

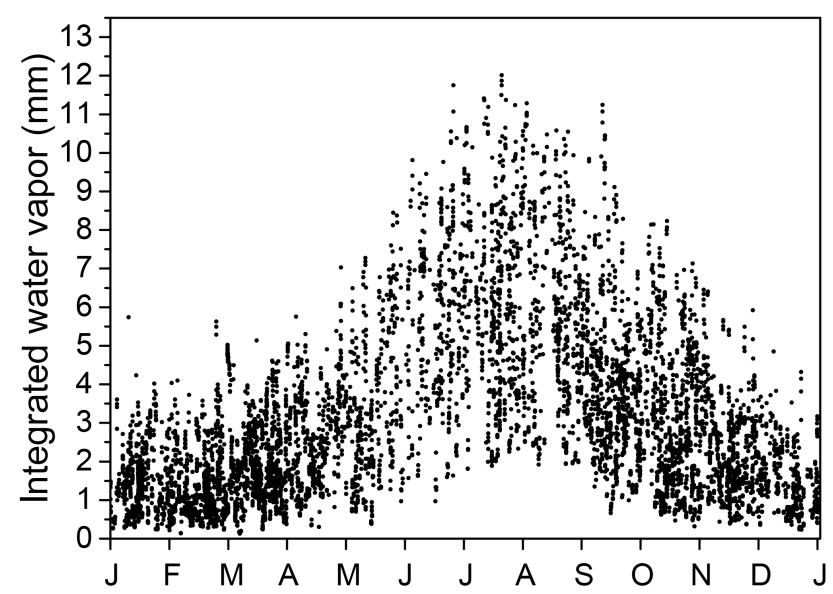

Figure 3. Climatology of integrated water vapor above the Zugspitze. Data are from multi-annual (1996-2013) Zugspitze solar FTIR measurements (clear sky, 15-20 min integration; see Sussmann et al., 2009, for details). See Table 1 for related statistics.

the use of the first 239 principal components is optimal. This resulted in a $\sim 50 \%$ noise reduction.

\subsection{NIR radiance measurements}

Solar absorption spectra in the NIR spectral range from 2500 to $7800 \mathrm{~cm}^{-1}(4.0-1.28 \mu \mathrm{m})$ were implemented via the Zugspitze high-resolution solar FTIR system based on a Bruker IFS $125 \mathrm{HR}$ interferometer with an optical path difference of up to $418 \mathrm{~cm}$ (Sussmann and Schäfer, 1997). This instrument has been operational since 1995 for spectrometric MIR trace gas measurements within the NDACC network. All details of the new NIR radiometric measurements are given in Part 2. Briefly, the NIR operations are utilizing an InSb detector along with a $\mathrm{KBr}$ beam splitter (InGas/ $\mathrm{CaF}_{2}$ optional), interferograms are recorded with an $\mathrm{OPD}_{\max }$ of $45 \mathrm{~cm}$ and averaged over four to eight scans for one spectrum (75-150 s integration time). Radiometric calibration is achieved by a novel approach utilizing a combination of the Langley calibration method and a hot blackbody calibration source $(<2000 \mathrm{~K})$ used for interpolating the calibration curve between the individual spectral Langley calibration points (see Part 2 for detailed information). Related NIR radiometric uncertainties are given in Table 1 and will be further discussed in Sect. 6.1.

\section{State measurements}

\subsection{Integrated water vapor and water vapor profiles}

For the closure experiments based on ER-AERI radiance measurements in the FIR and MIR, IWV is directly retrieved from ER-AERI spectra. This allows for an ideal spatiotemporal matching between the radiance measurements in the 
terrestrial infrared and the corresponding IWV state measurements. IWV is retrieved by minimizing ER-AERI vs. LBLRTM spectral residuals in IWV-sensitive windows. For this purpose we implemented an approach similar to the method proposed by Serio et al. (2008). Details of the IWV retrieval and the procedure for the selection of suitable spectral windows are outlined in Appendix A. Numbers for the uncertainty of the ER-AERI-based IWV retrieval are given in Table 1. The underlying uncertainty analysis is given in Appendix A, and Sect. 6 derives the related radiance uncertainty.

For the NIR closure measurements (Part 3), IWV was retrieved directly from the solar FTIR spectral radiance measurements (see Sect. 3.2) using an MIR retrieval scheme which exploits several spectral micro-windows in the 2610 $3050 \mathrm{~cm}^{-1}$ range (Schneider et al., 2012, 2016). Again, this allows for an ideal spatiotemporal matching of the solar infrared radiance measurements and the correlative IWV state measurements. Specifications of the uncertainty of the IWV retrieval from the solar FTIR are given in Table 1 and in Sect. 6.3, where the related radiance uncertainty is also presented.

Profile shape information on water vapor was taken from four-times-daily National Center for Environmental Prediction (NCEP) resimulation data. The reason for not using water vapor profiles from the low-humidity and temperature profiling (LHATPRO) microwave radiometer (Radiometer Physics, Germany; Rose et al., 2005) available on site is that a comparison of LHATPRO water vapor profiles with coincident NCEP resimulation profiles for the FIR continuum data set resulted in relatively large discrepancies, i.e., a mean precision $(2 \sigma)$ of $27.6 \%$ and a mean bias of $20.4 \%$. We therefore use NCEP profiles throughout the closure study. However, a comparison with LHATPRO profiles is used in order to detect and discard atmospheric states in which NCEP fails to realistically cover spatiotemporal variability of water vapor (see Sect. 7.1). An estimate of the NCEP profile shape uncertainty based on a comparison with radiosonde profiles is given in Table 1 and derived in Sect. 6.3.

\subsection{Temperature profiles}

Temperature profiles for the radiative transfer calculations were based on four-times-daily pressure-temperaturehumidity profiles from NCEP interpolated to the time of the radiance measurement. Since the lowest atmospheric layer above the Zugspitze summit is certainly influenced by the mountain surface, deviations between the true temperature profile and NCEP are expected. In order to account for this effect, the NCEP profile was corrected for the lowermost $500 \mathrm{~m}$ above the Zugspitze summit. The correction is retrieved using the spectral radiance observed by the ER-AERI in the central part of the $15 \mu \mathrm{m}$ band of $\mathrm{CO}_{2}$ (i.e., 625$\left.715 \mathrm{~cm}^{-1}\right)$. Because of the strong absorption, the measured radiance in this spectral region strongly correlates to the tem- perature of the environment close to the instrument. We use the retrieval scheme developed by Esposito et al. (2007) for this kind of boundary layer temperature inversion, which has been successfully utilized by a series of studies (Serio et al., 2008; Masiello et al., 2012; Liuzzi et al., 2014). A similar approach has been used by Rowe et al. (2006) and Rowe and Walden (2009). An estimate of the profile uncertainty based on a comparison with radiosonde profiles is given in Table 1 and derived in Sect. 6.3.

\subsection{Columns of $\mathrm{O}_{3}, \mathrm{CO}_{2}, \mathrm{CH}_{4}$, and $\mathrm{N}_{2} \mathrm{O}$}

Total columns of ozone are obtained from Brewer-Dobson soundings at the nearby Hohenpeißenberg observatory of the German Weather Service (Köhler, 1995) with an accuracy of $\sim 1 \%$ (Staehelin et al., 2003). The horizontal distance between Hohenpeißenberg $\left(47.80^{\circ} \mathrm{N}, 11.02^{\circ} \mathrm{E}\right.$; $985.5 \mathrm{~m}$ a.s.1.) and the Zugspitze is $\sim 40 \mathrm{~km}$. We used the ozone profile given by the midlatitude winter (MLW) standard atmosphere, which was scaled to the measured total column corrected by a factor of 0.982 . This correction is used to account for the altitude difference to the Zugspitze site and was deduced by calculating the fraction of the total ozone column between 985.5 and $2964 \mathrm{~m}$ a.s.l. according to the MLW standard atmosphere.

Column-averaged mixing ratios of carbon dioxide, methane, and nitrous oxide $\left(\mathrm{XCO}_{2}, \mathrm{XCH}_{4}, \mathrm{XN}_{2} \mathrm{O}\right)$ were inferred from solar FTIR measurements. Trace gas column measurements can be obtained with the Zugspitze solar FTIR, which is also used for the NIR radiance measurements in the closure experiment (see Fig. 1). However, for practical reasons (beam splitter change from $\mathrm{KBr}$ to $\mathrm{CaF}_{2}$ necessary for switch between MIR and NIR trace gas measurements but not possible via remote control), the NIR FTIR instrument operated at the nearby Garmisch site $\left(47.48^{\circ} \mathrm{N}, 11.06^{\circ} \mathrm{E}\right.$; 743 ma.s.1.) within the Total Carbon Column Observing Network (TCCON; http://www.tccon.caltech.edu) has been used for routine trace gas measurements. This is a suitable option because the horizontal distance between Garmisch and the Zugspitze is only $\sim 8 \mathrm{~km}$. The site altitude difference has been taken into account for $\mathrm{CH}_{4}$ and $\mathrm{N}_{2} \mathrm{O}$ because of the stratospheric slope of the mixing ratio profiles of these species. This has been performed by using the multi-annual mean ratio of column-averaged mixing ratios retrieved from the Zugspitze and Garmisch NDACC solar FTIR measurements of $1.8 \%$ (the underlying data sets are displayed in Fig. 1 of Sussmann et al., 2012). Uncertainties given in Table 1 were taken from the TCCON wiki (https://tccon-wiki.caltech.edu/Network_Policy/Data_ Use_Policy/Data_Description\#Sources_of_Uncertainty).

\subsection{Aerosol optical depth}

AOD is constrained using sun photometer measurements of the Sun-Sky Automatic RAdiometer (SSARA) instrument 
(Toledano et al., 2009) setup at Zugspitze-Schneefernerhaus (2675 $\mathrm{m}$ a.s.1.; $680 \mathrm{~m}$ horizontal distance to the Zugspitze solar FTIR). Our AOD retrieval and the derivation of the corresponding uncertainties given in Table 1 are outlined in detail in Part 3.

\section{Radiative transfer calculations}

Synthetic radiance spectra in the Zugspitze closure experiment were generated using the LBLRTM (Clough et al., 2005). The atmospheric state necessary as input to the model was set according to the measurements listed in Sect. 4. Parameters not constrained by measurements were set to the values given by the midlatitude winter standard atmosphere. For spectral line parameters, the aer_v3.2 line list provided alongside the LBLRTM model was used.

The calculations were carried out for a 39-level atmosphere from observer height (2964 ma.s.1.) to $120 \mathrm{~km}$ altitude. The altitude grid was chosen in order to keep the error from the discretization of the atmosphere in the calculations negligible compared to the remainder of the residual error budget $(2.8 \%$ of total uncertainty for water vapor continuum retrieval windows). Synthetic radiance spectra were convoluted with a sinc-type instrumental line shape (ILS) accounting for the $\mathrm{OPD}_{\max }$ relevant for the ER-AERI (see Knuteson et al., 2004b) and solar FTIR (see Sect. 3.2) measurements.

\section{Uncertainty analysis of radiance residuals}

A meaningful interpretation of the spectral residuals derived in the closure experiment relies on a comprehensive residual uncertainty budget. For this purpose, systematic and $2 \sigma$ statistical error estimates were set up for all significant individual uncertainty contributions. Radiance uncertainties were then calculated from input parameter uncertainties by multiplying them with the corresponding radiance derivatives. In the case of input profiles, state error covariance matrices were used. The radiance derivatives were calculated with the LBLRTM using the finite difference method, except for the $T$ profile radiance derivative matrix, which is calculated using the LBLRTM built-in analytic Jacobian capability.

\subsection{Uncertainty from spectral radiance measurements}

A first group of contributions to the uncertainty is associated with the ER-AERI spectral radiance measurements. An estimate of the ER-AERI measurement noise (Fig. 8a) is automatically generated by the ER-AERI software within the radiometric calibration procedure according to the method established by Revercomb et al. (1988). This noise estimate was reduced by $50 \%$ to account for the effect of the principal component analysis (PCA) filter applied to the spectra (see Sect. 4). The residuals, i.e., the radiance component identified as noise by the PCA filter is well represented by a normal distribution $\left(\right.$ mean $=8.5 \times 10^{-6} \mathrm{~mW}\left(\mathrm{~m}^{2} \mathrm{srcm}^{-1}\right)^{-1}, \quad \sigma=$ $0.21 \mathrm{~mW}\left(\mathrm{~m}^{2} \mathrm{sr} \mathrm{cm}^{-1}\right)^{-1}$ for the closure data set presented in Sect. 7.1). Further radiance uncertainty of the ER-AERI measurements ensues from radiometric calibration errors. The calibration uncertainty estimate was set according to Knuteson et al. (2004b), who demonstrate this contribution to be less than $0.67 \%$ ( $2 \sigma$ uncertainty) of the ambient blackbody radiance. According to the same authors, the repeatability (precision) is $0.13 \%(2 \sigma)$. The resulting absolute ER-AERI radiance uncertainty is shown in Fig. 8a as the purple line, which - divided by the grey ambient blackbody Planck curve - reflects the $0.67 \%$ relative calibration uncertainty cited.

Uncertainty contributions associated with the NIR radiance measurements are the solar FTIR measurement noise and the radiometric calibration uncertainty. The calibration uncertainty includes sources of uncertainty connected with the temporal stability of the calibration. These are due to variation of the instrument's field of view of the solar tracker mirrors and ice buildup on the detector causing additional absorption. We show in Fig. 9 the overall $2 \sigma$ calibration uncertainty (purple), which is between 0.6 and $1.7 \%$ of measured radiance. For a plot of individual contributions, we refer to Part 2 (Fig. 6 therein).

\subsection{Uncertainty from radiative transfer calculations}

The second group of contributions to the residual uncertainty is associated with the synthetic spectra calculation and the corresponding input for spectroscopic line parameters and atmospheric state. A further uncertainty contribution associated with the LBLRTM ensues from the discretization of the atmosphere used for the calculation. As outlined in Sect. 5, the layering was adjusted in order to keep the discretization error negligible compared to the remainder of the uncertainty budget.

Line parameter uncertainties for water vapor and further trace gases were set according to a combination of two uncertainty estimates: a first uncertainty specification is provided in the error codes of the aer_v3.2 line list provided alongside the LBLRTM. The uncertainty of each parameter was assumed to correspond to the mean of the error range specified by the error code value. Since the error codes may not provide realistic uncertainty specifications for all spectral lines, an additional line parameter uncertainty estimate was obtained by taking the difference between the line parameters in the HITRAN 2008 database compared to the HITRAN 2012 database, which was modified for FIR water lines according to the results of Delamere et al. (2010). To provide a conservative estimate, the uncertainty due to line parameter errors was set to the maximum value provided by these two alternative methods for each spectral point. 

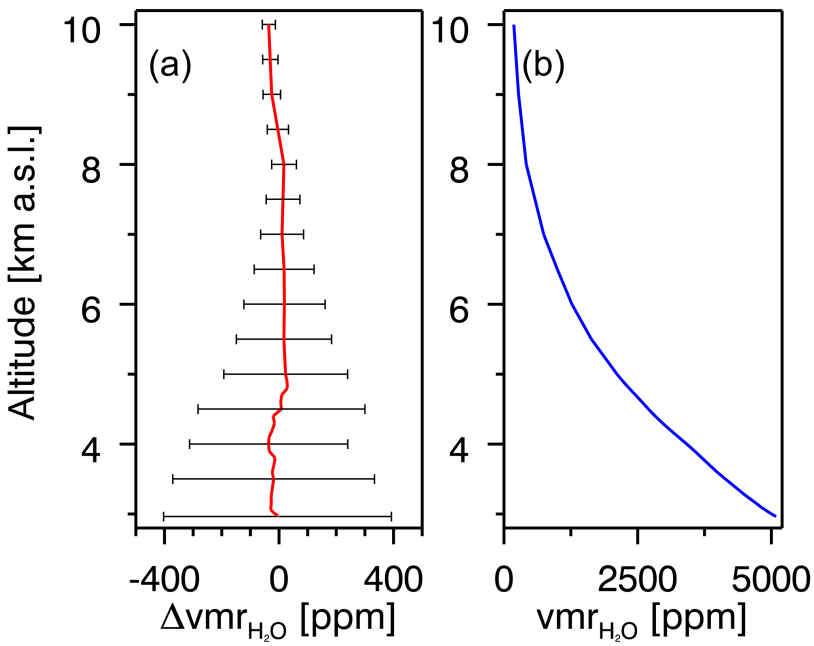

Figure 4. (a) Uncertainty analysis of NCEP water vapor profile shape. Red is the mean difference between NCEP profiles normalized with respect to IWV and an ensemble of best-estimate profiles derived from pairs of radiosondes launched with a $1 \mathrm{~h}$ separation (also normalized for IWV). Black error bars indicate $2 \sigma$ differences. (b) Mean water vapor profile used in the uncertainty analysis.

\subsection{Uncertainty from atmospheric-state measurements}

The uncertainties in IWV in the case of FIR and MIR closure experiments based on ER-AERI spectra are derived in Appendix A. For the FIR closure data set (detailed in Sect. 7), a mean IWV precision of $4.3 \%(2 \sigma)$ is achieved, while the mean IWV bias is $4.4 \%$. The resulting IWV-related radiance uncertainty is shown in Fig. 8 (blue).

In the case of the NIR closure using solar FTIR spectra, the uncertainty of the IWV retrieval (precision: $0.8 \%$; bias: $1.1 \%$ ) is provided in Schneider et al. (2012). The IWVrelated radiance uncertainty in the NIR is shown in Fig. 9 (blue).

In addition to the total water vapor column, erroneous input for the shape of the water vapor profiles from NCEP leads to errors in the synthetic radiance. A conservative estimate for this was inferred from a comparison of the NCEP profiles with radiosonde measurements. We used radiosonde data from a campaign performed close to the Zugspitze site between March and November 2002 (for details see Sussmann and Camy-Peyret, 2002, 2003; Sussmann et al., 2009). The campaign data set comprises a number of 181 pairs of radiosondes launched with a $1 \mathrm{~h}$ time separation, and each radiosonde pair has been combined to a best estimate of the state of the atmosphere according to the formalism by Tobin et al. (2006). Subsequently, both NCEP profiles and sondebased Tobin best-estimate profiles were normalized by IWV analogously to the analysis in the closure experiment described in Sect. 7, and then profile differences were computed. The red line in Fig. 4 shows the mean difference profile. The profile shape bias of $1.7 \%$ given in Table 1 is just a simple proxy that has been obtained as follows: for each pair of sonde and NCEP profiles, a difference vector was calculated. Each component of the average bias vector was then deduced as the mean of the absolute values of the corresponding components of the difference vectors. The statistical profile shape uncertainty was set up via an error covariance matrix constructed from the difference profiles between NCEP and sonde-based Tobin best-estimate profiles. This error covariance was used for the further statistical analysis of radiance uncertainty. Just to illustrate some properties of this covariance, the black error bars in Fig. 4 show the $2 \sigma$ statistical uncertainties of the difference profile (corresponding to the diagonal of the covariance). By calculating the mean of these error bars, we can derive a simple scalar proxy for the statistical profile uncertainty of $9.4 \%$ (Table 1). An estimate of the corresponding radiance uncertainty that includes the influence of layer-to-layer correlations can be obtained by multiplying the full error covariance matrix with the derivative matrix of radiance with respect to water vapor profile shape in the atmospheric layers (see Fig. 5) and its inverse. This leads to the residual uncertainty shown in Fig. 8 (pink). The representation in Fig. 5 corresponds to the radiance change associated with a $1 \%$ change in water vapor density in a given altitude layer and subsequent rescaling of the profile to the IWV obtained as outlined in Sect. A1. Due to the rescaling to a prescribed IWV, the $1 \%$ increase in water vapor density in a given layer is associated with a decrease in all other layers. Therefore, a $1 \%$ perturbation in the lowermost layer (2.96-4 km a.s.1.) corresponds to lowering the center of gravity of the water vapor profile and leads to a positive change in radiance, while for higher layers, the opposite is true. Due to the decrease in water vapor density with altitude (see Fig. 4b), the radiance effect of a $1 \%$ perturbation decreases rapidly with altitude.

The temperature profiles used in the closure study are a composite of $T$ profiles retrieved from the ER-AERI spectra for the altitude range between the Zugspitze up to $\sim 3.5 \mathrm{~km}$ a.s.l., while at higher altitude the $T$ profiles were set according to the NCEP reanalysis as described in Sect. 4 . The uncertainty estimate for these composite profiles was constructed from the same radiosonde campaign data as for the water vapor profile analysis outlined above. To generate an estimate of the uncertainty, synthetic radiance spectra were calculated using all radiosonde-derived best-estimate $T$ profiles from the campaign. The systematic part of the uncertainty was estimated by adding the ER-AERI calibration bias $(0.66 \%$, see Table 1$)$ and the estimated bias due to line parameter uncertainties (see Sect. 6.2) to the synthetic radiance spectra. Then, the near-surface temperature profile retrieval described in Sect. 4 was applied to the modified radiances. Finally, the differences between our composite $T$ profiles and the radiosonde-based best-estimate profiles from the campaign were calculated (red line in Fig. 6). Note, that the sign of the bias below $3.5 \mathrm{~km}$ a.s.l. (see Fig. 6) is arbitrary in the sense that it depends on whether the calibration bias is 


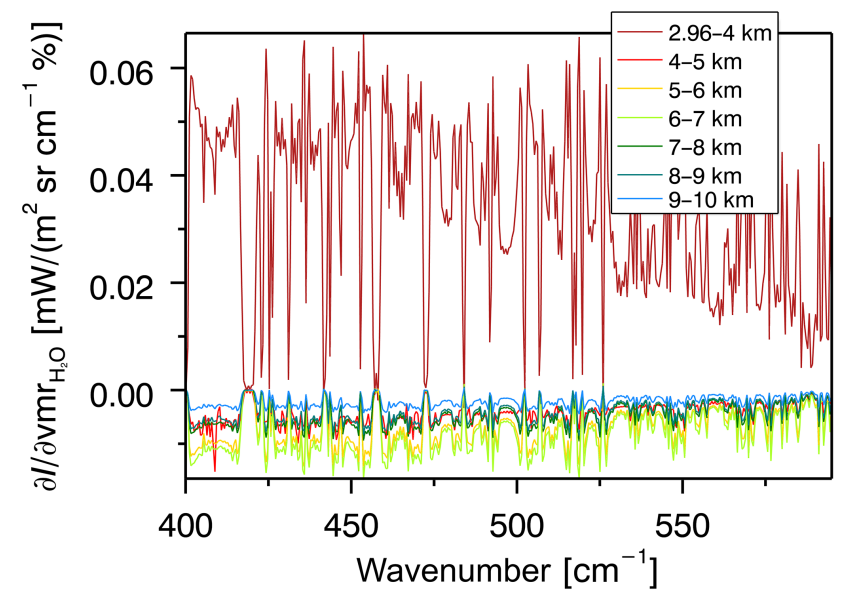

Figure 5. Derivative of surface downwelling radiance with respect to water vapor profile shape computed for the mean atmospheric state of the continuum retrieval data set. Color-coding indicates the contributions from different altitude layers.

added or subtracted. The random uncertainty of the composite $T$ profile was estimated by adding random error according to the statistical ER-AERI calibration uncertainty $(0.13 \%$, Table 1) and ER-AERI noise (yellow line in Fig. 8) to the synthetic radiance spectra. Finally, the near-surface temperature profile retrieval described in Sect. 4 was applied to the modified radiances. This approach implies that both the uncertainty due to the retrieval itself as well as additional uncertainty due to inaccurate radiance input are taken into account for the $T$ profile uncertainty estimate. An error covariance matrix estimate was then calculated from the difference of the radiosonde profiles to these composite $T$ profiles. Radiance uncertainties were then calculated by multiplication with the corresponding radiance derivative matrix depicted in Fig. 7. The resulting overall radiance uncertainties are shown in Figs. 4 and 5 (green).

Column uncertainties of further trace gases (see Table 2) are given by the TCCON specifications in the case of $\mathrm{CO}_{2}$, $\mathrm{CH}_{4}$, and $\mathrm{N}_{2} \mathrm{O}$ and the combined Brewer-Dobson measurement uncertainty for $\mathrm{O}_{3}$. The resulting radiance uncertainties are depicted in Figs. 4 and 5 (red and cyan).

An additional contribution ensues in the NIR from the AOD uncertainty, which is $<0.0015$ at $2500 \mathrm{~cm}^{-1}$ and $<0.0025$ at $7800 \mathrm{~cm}^{-1}$ at air mass 1 as detailed in Part 3 . The resulting radiance uncertainty is shown Fig. 9 (grey).

\subsection{Total uncertainty budget}

Figure 8 shows an estimate of the residual uncertainty in the FIR and MIR closure experiment using ER-AERI spectra; the same is shown in Fig. 9 for the solar FTIR radiative closure experiment in the NIR. The individual uncertainty contributions presented in Sects. 6.1-6.3 were added in quadrature to obtain the total residual uncertainty.

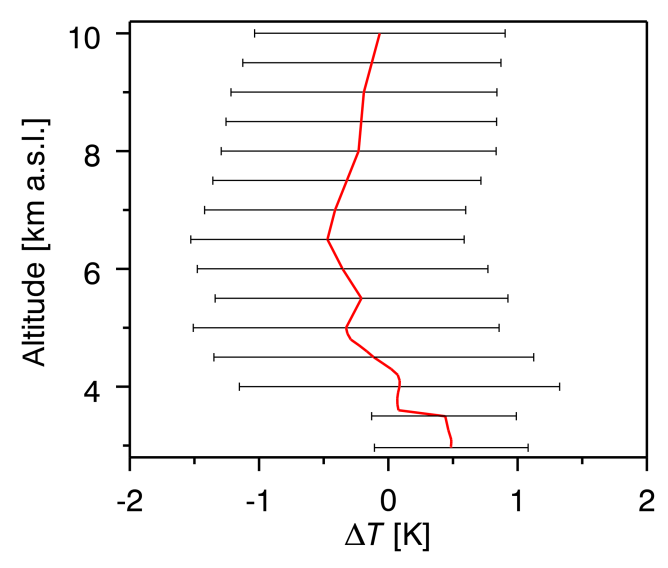

Figure 6. Uncertainty analysis of $T$ profiles used in the closure experiment (composite of ER-AERI retrievals $<3 \mathrm{~km}$ and NCEP). Red is the mean difference between these composite profiles and an ensemble of best-estimate profiles derived from pairs of radiosondes launched with a $1 \mathrm{~h}$ separation. Black error bars indicate $2 \sigma$ of the differences.

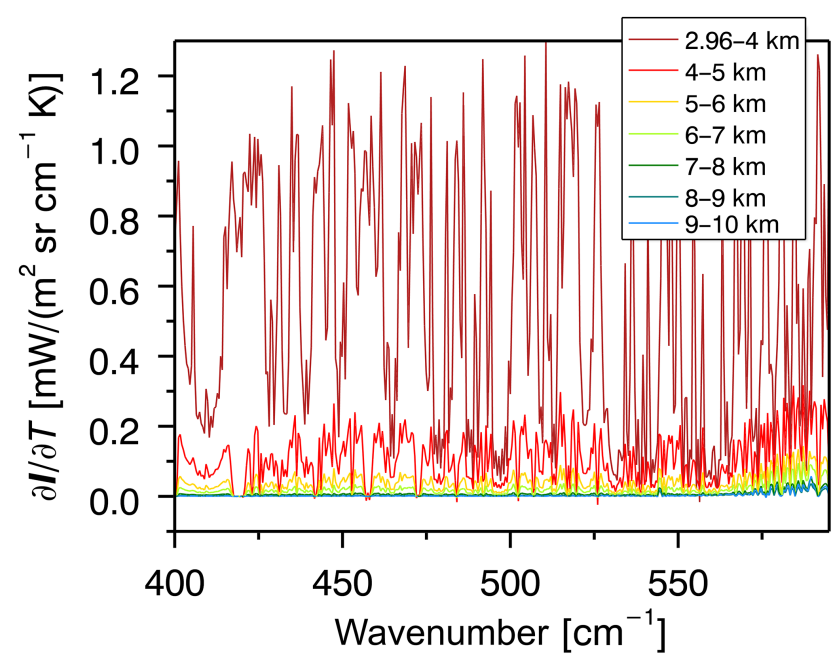

Figure 7. Derivative of surface downwelling radiance with respect to the $T$ profile computed for the mean atmospheric state of the continuum retrieval data set. Color-coding indicates the contributions from different altitude layers.

Figure $8 \mathrm{~d}$ shows that the dominant contribution to the total uncertainty in the FIR is from IWV uncertainty, water vapor profile shape uncertainty and partly water vapor line parameters in the windows used for continuum retrieval, while $T$ profile uncertainties dominate in the MIR (see Fig. 8a). Exceptions to this overall tendency do exist and are shown in Fig. 8b as an example for the FIR where a dominant role of $T$ profile uncertainties can be seen within saturated regions, e.g., around $420 \mathrm{~cm}^{-1}$. However, such saturated regions are not included in the spectral micro-windows used for continuum quantification (Fig. 8c). 

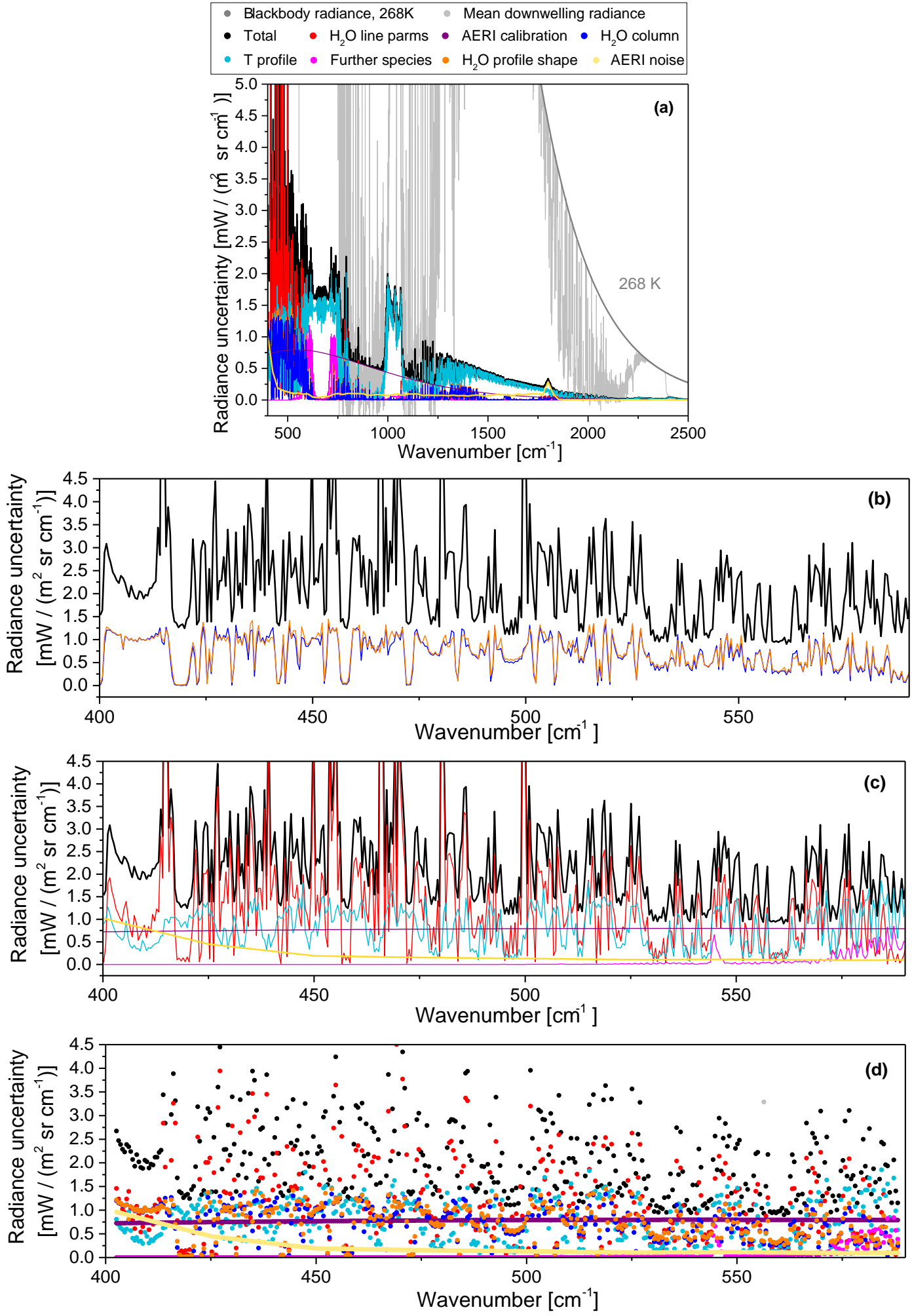

Figure 8. Residual uncertainty ( $2 \sigma$, relative to ambient BB radiance) of the FIR and MIR closure experiment for a single ER-AERI thermal emission spectrum and for the mean atmospheric state of the closure data set (IWV $=1.6 \mathrm{~mm}$; for more details see Sect. 7.1). (a) Individual error contributions (colors; red: "parms" stands for parameters) to the total residual uncertainty (black). For reference, a calculated radiance spectrum (grey) for the mean atmospheric state is shown along with the ambient BB Planck curve. (b, c) Zoom of (a) for the FIR part. (d) Same as (b, c) but restricted to the spectral windows used for continuum quantification. 


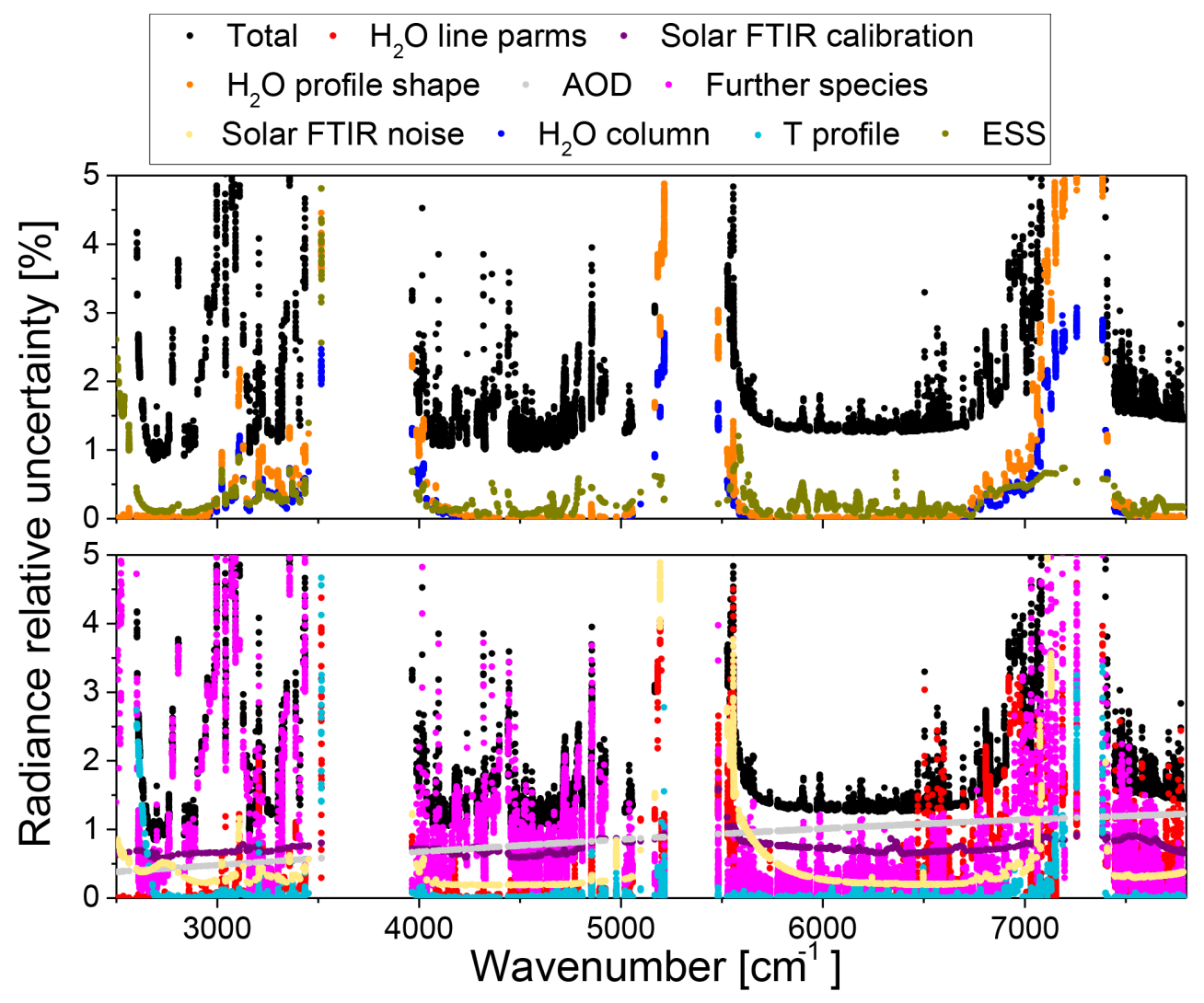

Figure 9. Residual uncertainty ( $2 \sigma$, relative to measured solar radiance) of the NIR closure experiment for a single solar FTIR spectrum and for the mean atmospheric state of the closure data set (IWV $=2.3 \mathrm{~mm}$; for more details, see Part 3). The total residual uncertainty (black) results from contributions by water vapor line parameter uncertainties (red; "parms" stands for parameters), IWV uncertainty (blue), temperature profile uncertainty (green), further trace gas column and line parameter uncertainties (cyan), AOD uncertainty (grey), solar FTIR calibration uncertainty (purple), and solar FTIR measurement noise (orange). Representation corresponds to the mean atmospheric state of the water vapor continuum quantification data set and the spectral windows used for continuum retrieval.

Uncertainty contributions to NIR radiance shown in Fig. 9 are dominated by varying contributions depending on wavelength. The overall uncertainty is dominated by water vapor line parameter uncertainties and water vapor profile shape uncertainty in the vicinity of the strong water vapor bands. The window regions in between are dominated by solar FTIR calibration uncertainties at low NIR wavenumbers, but uncertainties due to AOD become an increasing and dominant contribution towards higher NIR wavenumbers. Exceptions are methane or nitrous oxide bands in the NIR, where the associate line parameter uncertainties dominate the overall uncertainty.

\section{Example closure study: assessment of FIR continuum}

An example for a current research question that can be addressed with the closure setup presented in this publication is the magnitude of the water vapor continuum in the FIR spectral range. The Zugspitze closure experiment enables contin- uum quantification in the region $400-580 \mathrm{~cm}^{-1}$ based on a comparison of ER-AERI radiance spectra and LBLRTM results (see Fig. 10a).

\subsection{Spectra selection}

The example analysis is based on measurements carried out in the December 2013-February 2014 period. Several selection criteria were applied to the ER-AERI measurements in order to avoid bias in the quantification of the water vapor continuum. Clear-sky spectra were selected based on a radiance threshold in the MIR atmospheric window where significant thermal emission occurs only under cloudy conditions: the mean radiance in the 829 to $835 \mathrm{~cm}^{-1}$ window was required to be less than the synthetic radiance in this window plus the ER-AERI calibration uncertainty presented in Sect. 6.1.

Due to the reduced number of suitable windows for continuum retrieval under moist atmospheric conditions, we selected only spectra with IWV $<5 \mathrm{~mm}$. As outlined above, clear-sky conditions are a prerequisite for the closure mea- 


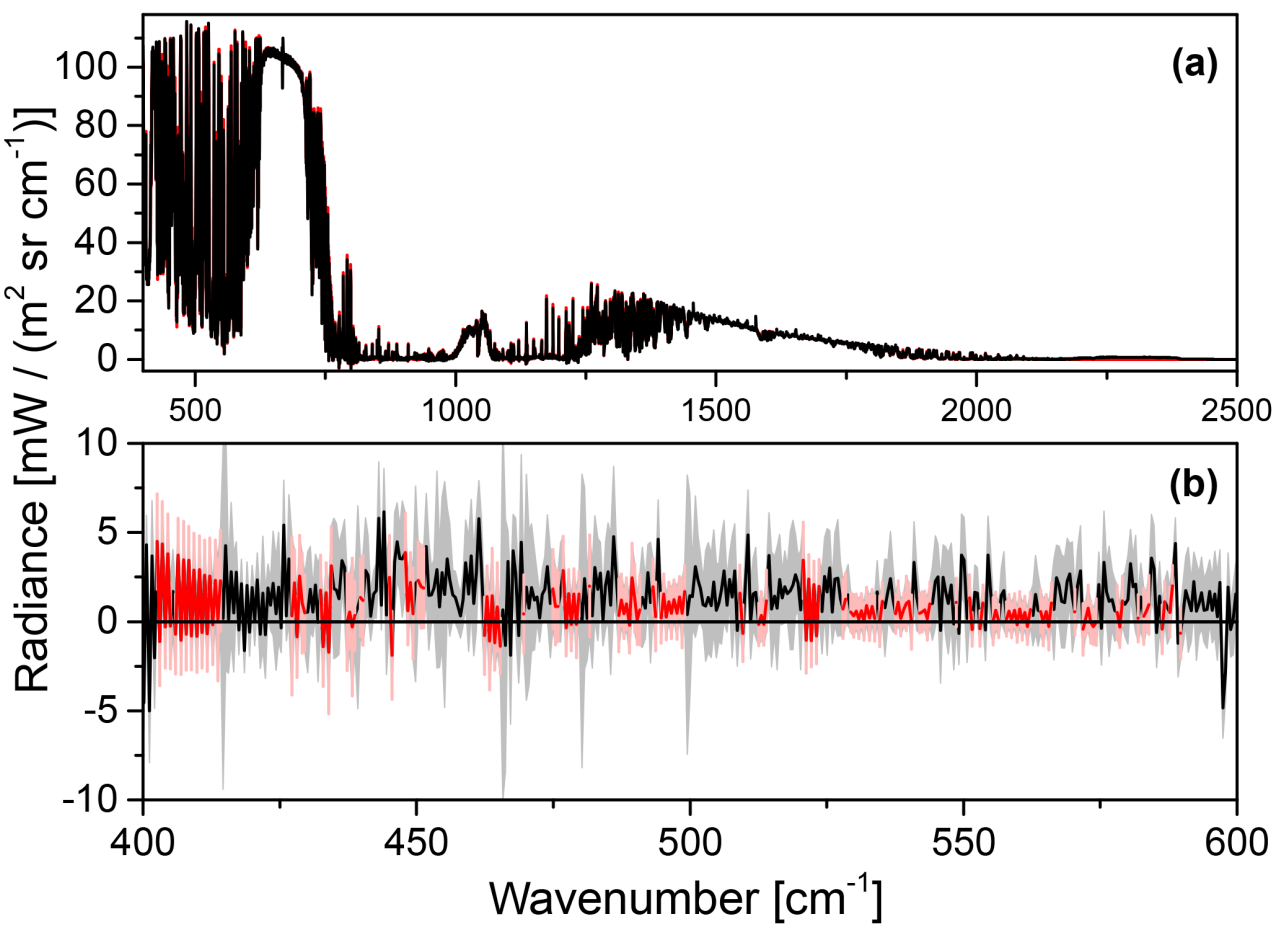

Figure 10. (a) Comparison of a measured ER-AERI spectrum (black) recorded on 13 December 2013, 08:28 UTC, and the corresponding synthetic LBLRTM spectrum (red). (b) Mean spectral residuals (synthetic minus measured radiances) derived from the continuum retrieval data set (black) and residual uncertainty (grey). Spectral windows used for continuum retrieval are highlighted in red.

surements. If, despite clear-sky conditions, the LHATPRO measurements indicate a high liquid water path (LWP), this indicates that snow has accumulated on the instrument and may bias the measurements. Therefore, we only selected spectra with $\mathrm{LWP}<100 \mathrm{~g} \mathrm{~m}^{-2}$. NCEP reanalysis data are used to constrain water vapor profile shape in the closure experiment. Despite the low uncertainties of the NCEP water vapor profiles demonstrated in Sect. 6.3, significant deviations from the real profile shape are expected in rare cases. This is due to the limited (6-hourly) time resolution of the NCEP data and their inability to reproduce small-scale spatial variability of water vapor concentrations. In order to identify these cases, we excluded measurements from further analysis if the mean difference of NCEP vs. LHATPRO water vapor profiles exceeded the $1 \sigma$ uncertainty of the LHATPRO measurements presented in Sect. 6.3. These criteria lead to a continuum retrieval data set of 211 spectra, selected from 2787 spectra measured in December 2013-February 2014.

\subsection{Window selection}

Spectral residuals, i.e., the difference between synthetic and measured spectra were calculated from the set of selected spectra. Figure 10b shows the mean residuals for our data set and their uncertainty according to the estimate provided in Sect. 6.
Accurate constraints on the water vapor continuum can only be derived from a number of spectral windows, whereas throughout the remainder of the spectrum the continuum does either not contribute significantly to the measured radiance or the residual uncertainty is too high. In order to select suitable windows, an estimate of the continuum uncertainty achievable in the closure experiment was determined by multiplying the residual uncertainty estimate (see Sect. 6) with the continuum Jacobian. The continuum Jacobian, i.e., the derivative of continuum magnitude with respect to measured downwelling radiance, was calculated via the finite difference method using the MT_CKD 2.5.2 model as a priori. We selected windows for further analysis for which the continuum uncertainty is less than $100 \%$ above the minimum uncertainty in $10 \mathrm{~cm}^{-1}$ wide bins. The selected windows are highlighted in red in Fig. 10b.

\subsection{Continuum quantification procedure}

Continuum quantification is achieved via an iterative minimization of spectral residuals in the selected windows. Spectral residuals in the windows are interpreted to be due to inaccurate foreign continuum since the radiance contribution by the self-continuum is assumed to be negligible given the spectral range and the dry atmospheric conditions. Mean adjusted continuum coefficients are calculated in $10 \mathrm{~cm}^{-1}$ wide 


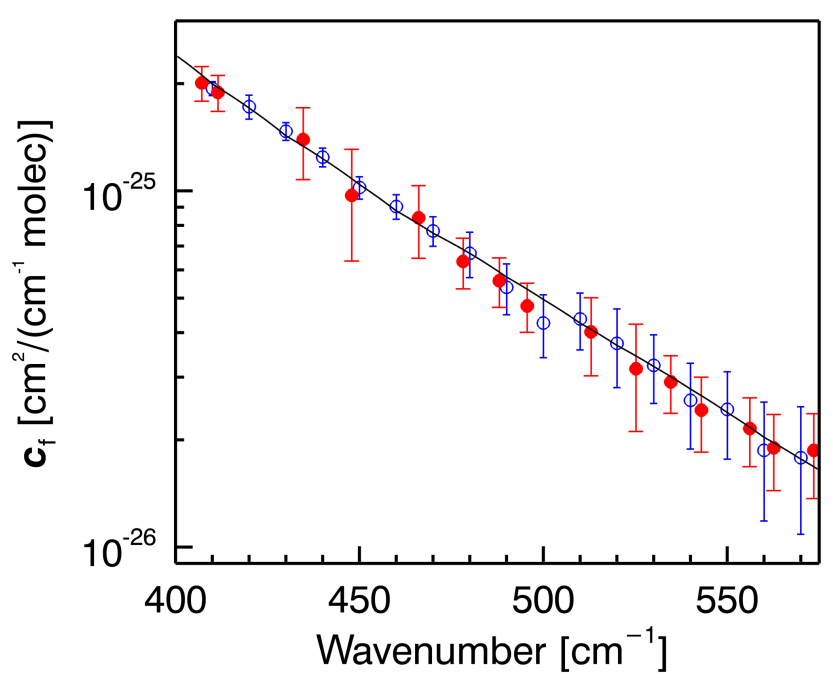

Figure 11. Mean foreign-continuum coefficients derived from the Zugspitze closure measurements (red) in comparison to the MT_CKD 2.5.2 model (black) and the results of Liuzzi et al. (2014) (blue).

bins to reduce influence of the measurement noise and ILS uncertainty on the results.

The individual analysis steps comprise a determination of the spectral residuals in the selected windows and subsequent adjustment of the continuum according to these results and the continuum Jacobian. Synthetic radiance is then recalculated using the adjusted continuum input. This process is repeated iteratively until the mean spectral residuals in all bins are below $10 \%$ of the residual uncertainty estimate.

\subsection{Results}

Figure 11 shows the mean foreign-continuum coefficients determined from the Zugspitze data set in $10 \mathrm{~cm}^{-1}$ wide bins. Table 3 contains our results in tabulated form. The results are fully consistent with the MT_CKD 2.5.2 model given the continuum uncertainty estimate according to Sect. 6 . As visible in Fig. 11, our results are also fully consistent with the findings of Liuzzi et al. (2014) that were obtained in a comparable atmospheric closure study carried out in Antarctica.

\section{Summary and conclusions}

After a review of the state of the art in quantifying water vapor radiative processes, we have detailed the instrumental setup of the new Zugspitze long-term radiative closure field experiment designed to cover the terrestrial and solar infrared between 400 and $7800 \mathrm{~cm}^{-1}(1.28-25 \mu \mathrm{m})$. As a benefit for such experiments, the Zugspitze mountain site frequently encounters atmospheric states with very low IWV (minimum $=0.1 \mathrm{~mm}$; median $=2.3 \mathrm{~mm})$ and very low AOD $\left(0.0024-0.0032\right.$ at $7800 \mathrm{~cm}^{-1}$ at air mass 1$)$. We also pro-
Table 3. Mean foreign-continuum coefficients derived from the Zugspitze closure measurements and associated $(2 \sigma)$ uncertainties.

\begin{tabular}{rc}
\hline $\begin{array}{r}\text { Wavenumber } \\
\left(\mathrm{cm}^{-1}\right)\end{array}$ & $c_{f}\left(\mathrm{~cm}^{2}\left(\mathrm{~cm}^{-1} \mathrm{molec}\right)^{-1}\right)$ \\
\hline 407.12 & $2.01 \times 10^{-25} \pm 2.24 \times 10^{-26}$ \\
411.51 & $1.89 \times 10^{-25} \pm 2.18 \times 10^{-26}$ \\
434.69 & $1.39 \times 10^{-25} \pm 3.17 \times 10^{-26}$ \\
447.89 & $9.71 \times 10^{-26} \pm 3.36 \times 10^{-26}$ \\
466.09 & $8.40 \times 10^{-26} \pm 1.94 \times 10^{-26}$ \\
478.18 & $6.33 \times 10^{-26} \pm 1.03 \times 10^{-26}$ \\
488.02 & $5.59 \times 10^{-26} \pm 8.86 \times 10^{-27}$ \\
495.61 & $4.75 \times 10^{-26} \pm 7.48 \times 10^{-27}$ \\
512.96 & $4.02 \times 10^{-26} \pm 9.93 \times 10^{-27}$ \\
525.18 & $3.17 \times 10^{-26} \pm 1.05 \times 10^{-26}$ \\
534.65 & $2.91 \times 10^{-26} \pm 5.35 \times 10^{-27}$ \\
542.95 & $2.42 \times 10^{-26} \pm 5.75 \times 10^{-27}$ \\
556.13 & $2.15 \times 10^{-26} \pm 4.70 \times 10^{-27}$ \\
562.64 & $1.90 \times 10^{-26} \pm 4.58 \times 10^{-27}$ \\
573.53 & $1.87 \times 10^{-26} \pm 4.99 \times 10^{-27}$ \\
585.36 & $1.22 \times 10^{-26} \pm 5.38 \times 10^{-27}$ \\
\hline
\end{tabular}

vided an uncertainty estimate for all measurements and retrieval procedures.

Given the instrumental uncertainties we assessed the sensitivity of the field experiment with respect to the information attainable, e.g., on the water vapor continuum. This was performed by setting up a systematic residual radiance uncertainty budget for the radiative closure over the whole spectral range of the experiment. The dominant uncertainty contribution in the FIR is from IWV uncertainty, water vapor profile shape uncertainty, and partly water vapor line parameters in the windows used for continuum retrieval, while $T$ profile uncertainties dominate in the MIR. Exceptions to this overall tendency do exist, e.g., for the FIR where a dominant role of $T$ profile uncertainties is found within saturated regions. However, such saturated regions are not included in the spectral micro-windows used for continuum quantification. Uncertainty contributions to NIR radiance residuals are dominated by varying contributions depending on wavelength. The overall uncertainty is dominated by water vapor line parameter uncertainties or water vapor profile shape uncertainty in the vicinity of the strong water vapor bands. The window regions in between are dominated by solar FTIR calibration uncertainties at low NIR wavenumbers, but uncertainties due to AOD become an increasing and dominant contribution towards higher NIR wavenumbers. Exceptions are methane or nitrous oxide bands in the NIR, where the associated line parameter uncertainties dominate the overall uncertainty.

Finally, we showed a water vapor continuum quantification in the FIR spectral region $\left(400-580 \mathrm{~cm}^{-1}\right)$ and detailed all procedures involved, like spectral micro-window and data quality selection. The FTIR foreign-continuum coefficients 
determined from the Zugspitze data set are consistent both with the MT_CKD 2.5.2 model and the recent atmospheric closure study carried out in Antarctica by Liuzzi et al. (2014).

Two companion papers - Part 2 (Reichert et al., 2016) and Part 3 (Reichert and Sussmann, 2016) - will show details on the development of a radiometric calibration of the Zugspitze solar FTIR system for NIR radiance measurements and its application to derive first information on the NIR water vapor continuum under atmospheric conditions.

Future work aims at extending our studies from water vapor radiative closure to also include a quantification of the radiative properties of cirrus clouds. Because of the regionally varying radiative properties of cirrus, it is important to perform such studies at various field sites around the globe.

\section{Data availability}

The data underlying Fig. 9 (mean FIR foreign-continuum coefficients) are results of generic use and have therefore explicitly been listed in Table 3 as numbers. The remaining figures (describing the radiative closure setup and the uncertainty analysis) are illustrations specific to the Zugspitze site. The underlying data can be obtained at any time from the corresponding author on demand. 


\section{Appendix A: Retrieval of IWV from ER-AERI spectra}

\section{A1 Retrieval method}

We utilize an approach similar to the method proposed by Serio et al. (2008), i.e., IWV is retrieved via a derivative approach using one iteration to minimize ER-AERI vs. LBLRTM spectral residuals in IWV-sensitive windows. As first-guess IWV, data from a LHATPRO microwave radiometer are used. LHATPRO (Radiometer Physics, Germany; Rose et al., 2005), designed for ultra low-humidity sites (IWV $<4.0 \mathrm{~mm}$ ), is a microwave radiometer located side-by-side with the ER-AERI. It measures sky brightness temperatures in six channels within the strong $183.31 \mathrm{GHz}$ water vapor line with a repeat cycle of $1 \mathrm{~s}$ for IWV and 60 s for profiles (Radiometer Physics, 2013). The Radiometer Physics software (Radiometer Physics, 2014) allows for statistical retrieval of water vapor profiles which is based on a neuronal network approach (Jung et al., 1998) utilizing MWMOD (MicroWave MoDel) radiative calculations (Simmer, 1994) performed for a radiosonde training data set. However, the IWV results obtained with the LHATPRO show a significant bias compared to an IWV retrieval from solar FTIR spectra (Sussmann et al., 2009), which has been extensively validated against other instruments (see Sussmann et al., 2009; Vogelmann et al., 2011). The solar FTIR-based IWV retrieval is not suitable as input to the FIR closure study is because few coincident measurements of ER-AERI and solar FTIR are available. We therefore chose to implement the IWV retrieval procedure outlined below.

The procedure for the selection of suitable spectral windows for IWV retrieval from the $400-600 \mathrm{~cm}^{-1}$ spectral range has been implemented as follows:

i. The uncertainty of the IWV fit for single spectral points is calculated for the remaining windows. IWV relative uncertainty is given as the residual uncertainty excluding IWV contribution divided by $\partial \boldsymbol{I} / \partial \mathrm{IWV}$, i.e., the derivative of downwelling spectral radiance $\boldsymbol{I}$ with respect to IWV. The overall uncertainty comprises two classes of errors, namely type i errors, which are uncorrelated between wavenumbers, and type ii errors correlated between wavenumbers. ER-AERI measurement noise is treated as a type i error contribution (the underlying assumption being that line parameter errors for different lines are independent). Other uncertainty contributions such as ER-AERI calibration, $T$ profile errors, and water vapor profile errors (see Sect. 6.3 for details) are correlated for different spectral channels (type ii). Line parameter errors may feature some correlation between wavenumbers due to systematic bias in the measurements used to constrain these parameters. To account for this, $50 \%$ of the radiance uncertainty associated with line parameter errors for any spectral point was treated as correlated between wavenumbers

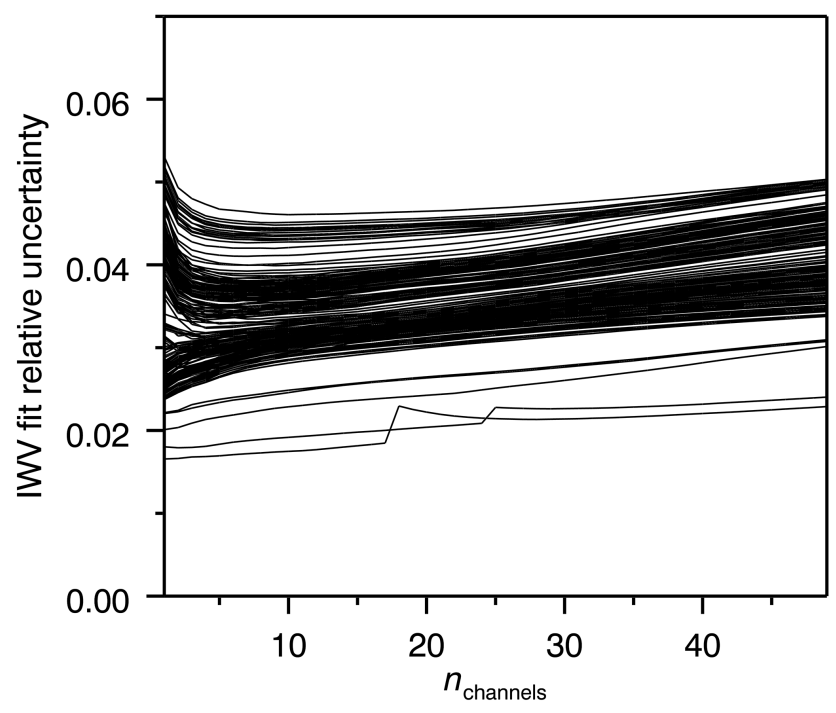

Figure A1. Relative uncertainty of the IWV fit depending on the number of spectral points $n_{\text {channels }}$ used in the fit for the spectra included in the FIR continuum data set. Channels are ordered by increasing type ii uncertainty. The number of channels used for the fit is adjusted in order to yield minimum overall uncertainty.

(type ii), while the remaining $50 \%$ were treated as uncorrelated (type i).

ii. Spectral points (channels) are ordered from lowest to highest type ii uncertainty.

iii. Ensembles with stepwise increased number of channels are constructed including channels with increasing type ii uncertainty, and the overall uncertainty (type $\mathrm{i}+\mathrm{ii}$ ) is calculated for each ensemble. Figure A1 shows this overall uncertainty depending on the number of included channels. Type i contributions to the cumulative uncertainty are reduced by a factor $1 / \sqrt{n}$ when $n$ channels are included in the fit (causing the decrease in uncertainty on the left-hand side of Fig. A1). For type ii contributions, no uncertainty reduction is achieved by including more channels in the fit, and the overall uncertainty increases toward the right-hand side of Fig. A1. This is because more and more channels with increasing type ii uncertainty are included.

iv. The optimum number of spectral channels for the fit is deduced from the minimum of overall (type $\mathrm{i}+\mathrm{ii}$ ) uncertainty (Fig. A1). The resulting optimum numbers of channels for the different spectra of our closure data set are shown in Fig. A2; the mean value is 4.1 channels, with a minimum of 1 and a maximum of 10 channels.

v. The IWV fit according to steps $\mathrm{i}-\mathrm{iv}$ is repeated for each iteration step of the continuum quantification procedure (see Sect. 7.3). This iterative approach serves to 


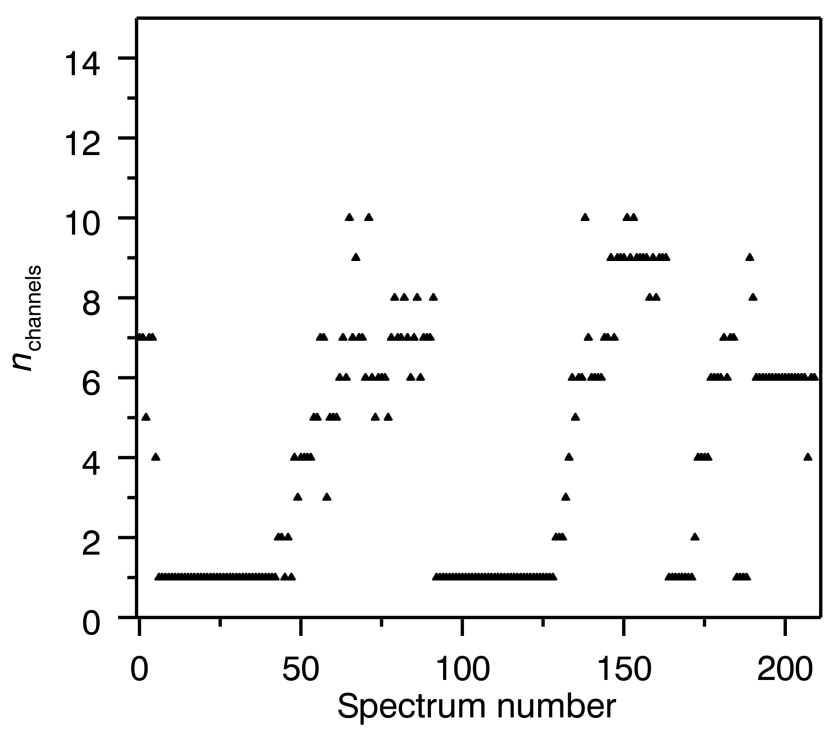

Figure A2. Number of spectral channels included in the IWV fit for the spectra of the FIR continuum data set. $n_{\text {channels }}$ was chosen according to the minimum uncertainty criterion shown in Fig. A1.

avoid interference between the continuum quantification and the IWV fit. Performing the IWV fit including only windows with negligible continuum contribution (i.e., excluding all windows with continuum uncertainty $<100 \%$ ) leads to a mean bias in the IWV results of $0.005 \mathrm{~mm}$. This negligible bias indicates that the iterative approach is able to avoid significant interference between IWV fit and water vapor continuum determination.

The results of the IWV fit for all spectra included in the FIR closure data set are shown in Fig. A3. The mean correction relative to the LHATPRO first-guess IWV was $-0.098 \mathrm{~mm}$, with a standard deviation of $0.089 \mathrm{~mm}$. This corresponds to a mean IWV correction of $4.1 \%$, which is slightly beyond the mean fit uncertainty of $3.1 \%$, i.e., the IWV fit leads to a significant improvement of the IWV input compared to using the LHATPRO data.

\section{A2 Uncertainty estimate}

An estimate of the statistical and systematic uncertainty of the IWV retrieval can be obtained based on the uncertainty of the ER-AERI-LBLRTM spectral residuals presented in Sect. 6 and Fig. 8.

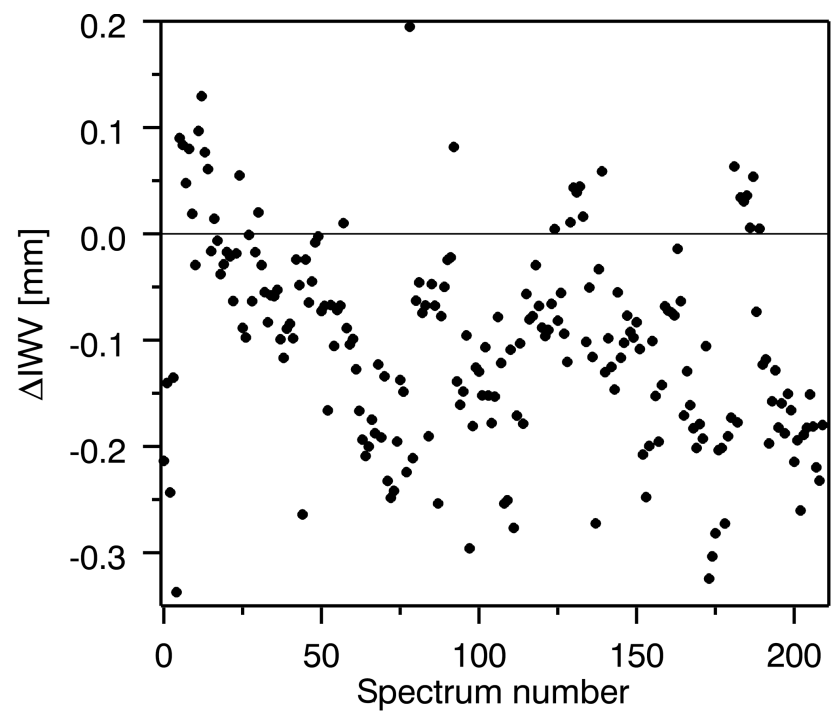

Figure A3. Adjustment $\triangle \mathrm{IWV}$ to the first-guess value

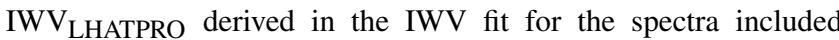
in the FIR continuum data set.

The statistical residual uncertainty is calculated as the quadratic sum of the ER-AERI measurement noise and the statistical uncertainties related to calibration, $T$ profiles, and water vapor profiles. The IWV fit uncertainty for single spectral points can be calculated as the statistical residual uncertainty divided by $\partial \boldsymbol{I} / \partial \mathrm{IWV}$. However, the IWV fit result is not derived from single spectral points but from an ensemble of points selected according to the criterion presented in Fig. A1. Therefore, the statistical IWV uncertainty for each spectrum is the error-weighted mean of the singlepoint contributions for all channels included in the ensemble. The mean statistical IWV uncertainty we achieve for the FIR closure data set (Sect. 7) is $1.9 \%(2 \sigma)$.

The systematic IWV uncertainty can be derived in an analogous way. Systematic error contributions due to line parameters, ER-AERI calibration, $T$ profiles, water vapor profiles, and columns of further species are summed up quadratically to calculate the systematic residual uncertainty. Using the same further analysis as outlined above for the statistical contribution, we obtain a mean systematic IWV uncertainty of $2.5 \%$ for the FIR closure data set. 
Acknowledgements. We thank the anonymous referees for their constructive and helpful comments, which led to significant improvements of this paper. We furthermore thank H. P. Schmid (KIT/IMK-IFU) for his continuous interest in this work and institutional support to purchase the LHATPRO. This project was funded by the Bavarian State Ministry of the Environment and Consumer Protection via grants TLK01U-49581 and VAO-II TPI/01. Andreas Reichert received a PhD grant of the Deutsche Bundesstiftung Umwelt (DBU). The authors are indebted to D. D. Turner (NOAA) and E. Mlawer (AER) for helpful conversations during the definition phase of the project; in particular, it is a pleasure to thank E. Mlawer for his suggestion to utilize the Zugspitze solar FTIR instrument for near-infrared radiative closure studies. We are grateful to P. Hausmann (KIT/IMK-IFU), who performed the solar FTIR water vapor retrievals. Thanks to U. Köhler (German Weather Service) for providing Brewer-Dobson data and M. Wiegner (LMU) for giving access to sun photometer measurements.

The article processing charges for this open-access

publication were covered by a Research

Centre of the Helmholtz Association.

Edited by: H. Maring

Reviewed by: three anonymous referees

\section{References}

Ackermann, T. P. and Stokes, G. M.: The Atmospheric Radiation Measurement program, Phys. Today, 56, 38-44, doi:10.1063/1.1554135, 2003.

Antonelli, P., Revercomb, H. E., Sromovsky, L. A., Smith, W. L., Knuteson, R. O., Tobin, D. C., Garcia, R. K., Howell, H. B., Huang, H.-L., and Best, F. A.: A principal component noise filter for high spectral resolution infrared measurements, J. Geophys. Res., 109, D23102, doi:10.1029/2004JD004862, 2004.

Baranov, Y. I. and Lafferty, W. J.: The water-vapour continuum and selective absorption in the 3 to $5 \mu \mathrm{m}$ spectral region at temperatures from 311 to 363 K, J. Quant. Spectrosc. Ra., 112, 13041313, doi:10.1016/j.jqsrt.2011.01.024, 2011.

Baranov, Y. I. and Lafferty, W. J.: The water vapour self- and water-nitrogen continuum absorption in the 1000 and $2500 \mathrm{~cm}^{-1}$ atmospheric windows, Philos. T. R. Soc. A, 370, 2578-2589, doi:10.1098/rsta.2011.0234, 2012.

Bhawar, R., Bianchini, G., Bozzo, A.,Cacciani, M., Calvello, M.R., Carlotti, M., Castagnoli, F., Cuomo, V., Di Girolamo, P., Di Iorio, T., Di Liberto, L.,di Sarra, A., Esposito, F., Fiocco, G., Fuà, D., Grieco, G., Maestri, T., Masiello, G., Muscari, G., Palchetti, L., Papandrea, E., Pavese, G., Restieri, R., Rizzi, R., Romano, F., Serio, C., Summa, D., Todini, G., and Tosi, E.: Spectrally resolved observations of atmospheric emitted radiance in the $\mathrm{H}_{2} \mathrm{O}$ rotation band, Geophys. Res. Lett., 35, L04812, doi:10.1029/2007GL032207, 2008.

Bianchini, G., Palchetti, L., Muscari, G., Fiorucci, I., Di Girolamo, P., and Di Iorio, T.: Water vapor sounding with the far infrared REFIR-PAD spectroradiometer from a high-altitude groundbased station during the ECOWAR campaign, J. Geophys. Res., 116, D02310, doi:10.1029/2010JD014530, 2011.
Bicknell, W. E., Cecca, S. D., Griffin, M. K., Swartz, S. D., and Flusberg, A.: Search for low absorption regions in the 1.6 and $2.1 \mu \mathrm{m}$ atmospheric windows, J. Directed Energ., 2, 151-161, 2006.

Clough, S. A., Shephard, M. W., Mlawer, E. J., Delamere, J. S., Iacono, M. J., Cady-Pereira, K., Boukabara, S., and Brown, P. D.: Atmospheric radiative transfer modeling: a summary of the AER codes, J. Quant. Spectrosc. R., 91, 233-244, doi:10.1016/j.jqsrt.2004.05.058, 2005.

DeAngelis, A. M., Qu, X., Zelinka, M. D., and Hall, A.: An observational radiative constraint on hydrologic cycle intensification, Nature, 528, 249-253, doi:10.1038/nature15770, 2015.

Delamere, J. S., Clough, S. A., Payne, V. H., Mlawer, E. J., Turner, D. D., and Gamache, R. R.: A far-infrared radiative closure study in the Arctic: Application to water vapor, J. Geophys. Res., 115, D17106, doi:10.1029/2009JD012968, 2010.

Esposito, F., Grieco, G., Masiello, G., Pavese, G., Restieri, R., Serio, C., and Cuomo, V.: Intercomparison of lineparameter spectroscopic databases using downwelling spectral radiance, Q. J. Roy. Meteorol. Soc., 133, 191-202, doi:10.1002/qj.131, 2007.

Frankenberg, C., Bergamaschi, P., Butz, A., Houweling, S., Meirink, J. F., Notholt, J., Petersen, A. K., Schrijver, H., Warneke, T., and Aben, I.: Tropical methane emissions: A revised view from SCIAMACHY onboard ENVISAT, Geophys. Res. Lett., 35, L15811, doi:10.1029/2008GL034300, 2008.

Held, I. M. and Soden, B. J.: Water vapor feedback and global warming, Annu. Rev. Energy Environ., 25, 441-475, doi:10.1146/annurev.energy.25.1.441, 2000.

Jung, T., Ruprecht, E., and Wagner, F.: Determination of cloud liquid water path over the oceans from SSM/I data using neural networks, J. Appl. Meteorol., 37, 832-844, doi:10.1175/15200450(1998)037<0832:DOCLWP>2.0.CO;2, 1998.

Kämpfer, N.: Monitoring atmospheric water vapour, Ground-Based Remote Sensing and In-situ Methods, ISSI Scientific Report Series, Vol. 10, Springer, New York, doi:10.1007/978-1-46143909-7, 2013.

Kiehl, J. T. and Trenberth, K. E.: Earth's annual global mean energy budget, Bull. Am. Meteorol. Soc., 78, 197-208, doi:10.1175/1520-0477(1997)078<0197:EAGMEB>2.0.CO;2, 1997.

Knuteson, R. O., Revercomb, H. E., Best, F. A., Ciganovich, N. C., Dedecker, R. G., Dirkx, T. P., Ellington, S. C., Feltz, W. F., Garcia, R. K., Howell, H. B., Smith, W. L., Short, J. F., and Tobin, D. C.: Atmospheric Emitted Radiance Interferometer. Part I: Instrument Design, J. Atmos. Ocean. Technol., 21, 1763-1776, doi:10.1175/JTECH-1662.1, 2004a.

Knuteson, R. O., Revercomb, H. E., Best, F. A., Ciganovich, N. C., Dedecker, R. G., Dirkx, T. P., Ellington, S. C., Feltz, W. F., Garcia, R. K., Howell, H. B., Smith, W. L., Short, J. F., and Tobin, D. C.: Atmospheric Emitted Radiance Interferometer. Part II: Instrument Performance, J. Atmos. Ocean. Tech., 21, 1777-1789, doi:10.1175/JTECH-1663.1, 2004b.

Köhler, U.: Homogenization and Re-evaluation of the Long-Term Ozone Series at the Met. Obs. Hohenpeissenberg, Final Report of the DWD-Project K/U 31, Deutscher Wetterdienst., Meterologisches Observatorium Hohenpeissenberg, 1995.

Liuzzi, G., Masiello, G., Serio, C., Palchetti, L., and Bianchini, G.: Validation of $\mathrm{H}_{2} \mathrm{O}$ continuum absorption models in the wave number range $180-600 \mathrm{~cm}^{-1}$ with atmospheric emitted spectral 
radiance measured at the Antarctica Dome-C site, Opt. Express, 22, 16784-16801, doi:10.1364/OE.22.016784, 2014.

Lohmann, U. and Bennartz, R.: Impact of improved near-infrared water vapor line data in simulations with the ECHAM4 general circulation model, J. Geophys. Res., 107, 4288, doi:10.1029/2001JD001101, 2002.

Mariani, Z., Strong, K., Wolff, M., Rowe, P., Walden, V., Fogal, P. F., Duck, T., Lesins, G., Turner, D. S., Cox, C., Eloranta, E., Drummond, J. R., Roy, C., Turner, D. D., Hudak, D., and Lindenmaier, I. A.: Infrared measurements in the Arctic using two Atmospheric Emitted Radiance Interferometers, Atmos. Meas. Tech., 5, 329-344, doi:10.5194/amt-5-329-2012, 2012.

Masiello, G., Serio, C., Esposito, F., and Palchetti, L.: Validation of line and continuum spectroscopic parameters with measurements of atmospheric emitted spectral radiance from far to mid infrared wave number range, J. Quant. Spectrosc. Ra., 113, 1286-1299, doi:10.1016/j.jqsrt.2012.01.019, 2012.

Mlawer, E., Gombos, D., Alvarado, M., Cady-Pereira, K., Payne, V., Chase, A., and Michalsky, J.: Determination of Near-IR Water Vapor Self Continuum from Field Observations, The 13th Biennial HITRAN Conference (HITRAN13), HarvardSmithsonian Center for Astrophysics, Cambridge, MA, USA, doi:10.5281/zenodo.11107, 2014.

Mlawer, E. J., Taubmann, S. J., Brown, P. D., Iacono, M. J., and Clough, S. A.: Radiative transfer for inhomogeneous atmospheres: RRTM, a validated correlated-k model for the longwave, J. Geophys. Res., 102, 16663-16682, doi:10.1029/97JD00237, 1997.

Mlawer, E. J., Payne, V. H., Moncet, J., Delamere, J. S., Alvarado, M. J., and Tobin, D.C.: Development and recent evaluation of the MT_CKD model of continuum absorption, Philos. T. R. Soc. A, 370, 2520-2556, doi:10.1098/rsta.2011.0295, 2012.

Mondelain, D., Aradj, A., Kassi, S., and Campargue, A.: The water vapour self-continuum by CRDS at room temperature in the $1.6 \mu \mathrm{m}$ transparency window, J. Quant. Spectrosc. Ra., 130, 381391, doi:10.1016/j.jqsrt.2013.07.006, 2013.

Mondelain, D., Vasilchenko, S., Čermák, P., Kassi, S., and Campargue, A.: The self- and foreign-absorption continua of water vapor by cavity ring-down spectroscopy near $2.35 \mu \mathrm{m}$, Phys. Chem. Chem. Phys., 17, 17762-17770, doi:10.1039/c5cp01238d, 2015.

Pfeilsticker, K., Lotter, A., Peters, C., and Bösch, H.: Atmospheric Detection of Water Dimers via Near-Infrared Absorption, Science, 300, 2078-2080, doi:10.1126/science.1082282, 2003.

Paynter, D. J. and Ramaswamy, V.: Variations in water vapor continuum radiative transfer with atmospheric conditions, J. Geophys. Res., 117, D16310, doi:10.1029/2012JD017504, 2012.

Paynter, D. J. and Ramaswamy, V.: Investigating the impact of the shortwave water vapor continuum upon climate simulations using GFDL global models, J. Geophys. Res.-Atmos., 119, 1072010737, doi:10.1002/2014JD021881, 2014.

Paynter, D. J., Ptashnik, I. V., Shine, K. P., and Smith, K. M.: Pure water vapor continuum measurements between 3100 and $4400 \mathrm{~cm}^{-1}$ : Evidence for water dimer absorption in near atmospheric conditions, Geophys. Res. Lett., 34, L12808, doi:10.1029/2007GL029259, 2007.

Paynter, D. J., Ptashnik, I. V., Shine, K. P., Smith, K. M., McPheat, R., and Williams, R. G.: Laboratory measurements of the water vapour continuum in the $1200-8000 \mathrm{~cm}^{-1}$ region between $293 \mathrm{~K}$ and $351 \mathrm{~K}$, J. Geophys. Res., 114, D21301, doi:10.1029/2008JD011355, 2009.

Ptashnik, I. V.: Evidence for the contribution of water dimers to the near-IR water vapour self-continuum, J. Quant. Spectrosc. Ra., 109, 831-852, doi:10.1016/j.jqsrt.2007.09.004, 2008.

Ptashnik, I. V., Smith, K. M., Shine, K. P., and Newnham, D. A.: Laboratory measurements of water vapour continuum absorption in spectral region $5000-5600 \mathrm{~cm}^{-1}$ : evidence for water dimers, Q. J. Roy. Meteor. Soc., 130, 2391-2408, doi:10.1256/qj.03.178, 2004.

Ptashnik, I. V., McPheat, R. A., Shine, K. P., Smith, K. M., and Williams, R. G.: Water vapor self-continuum absorption in nearinfrared windows derived from laboratory measurements, J. Geophys. Res., 116, D16305, doi:10.1029/2011JD015603, 2011.

Ptashnik, I. V., McPheat, R. A., Shine, K. P., Smith, K. M., and Williams, R. G.: Water vapour foreign continuum absorption in near-infrared windows from laboratory measurements, Philos. T. R. Soc. A, 370, 2557-2577, doi:10.1098/rsta.2011.0218, 2012.

Ptashnik, I. V., Petrova, T. M., Ponomarev, Y. N., Shine, K. P., Solodov, A. A., and Solodov, A. M.: Near-infrared water vapour self-continuum at close to room temperature, J. Quant. Spectros. Ra., 120, 23-35, doi:10.1016/j.jqsrt.2013.02.016, 2013.

Ptashnik, I. V., Petrova, T. M., Ponomarev, Yu. N., Solodov, A. A., and Solodov, A. M.: Water Vapor Continuum Absorption in Near-IR Atmospheric Windows, Atmos. Oceanic Opt., 28, 115120, doi:10.1134/S1024856015020098, 2015.

Rädel, G., Shine, K. P., and Ptashnik, I. V.: Global radiative and climate effect of the water vapour continuum at visible and nearinfrared wavelengths, Q. J. Roy. Meteor. Soc., 141, 727-738, doi:10.1002/qj.2385, 2015.

Revercomb, H. E., Buijs, H., Howell, H. B., LaPorte, D. D., Smith, W. L., and Sromovsky, L. A.: Radiometric calibration of IR Fourier transform spectrometers: Solution to a problem with the High-Resolution Interferometer Sounder, Appl. Optics, 27, 3210-3218, doi:10.1364/AO.27.003210, 1988.

Radiometer Physics: Technical Instrument Manual (Standard Radiometers), RPG-MWR-STD-TM, Issue 01/02, 41 pp., available at: http://www.radiometer-physics.de/download/PDF/ Radiometers/General_documents/Manuals/2015/RPG_MWR STD_Technical_Manual_2015.pdf (last access: 15 September 2016), 2013.

Radiometer Physics: Instrument Operation and Software Guide (Standard Radiometers), RPG-MWR-STD-SW, Issue 01/09, 170 pp., available at: http://www.radiometer-physics.de/ download/PDF/Radiometers/General_documents/Manuals/ 2015/RPG_MWR_STD_Software_Manual\%202015.pdf (last access: 15 September 2016), 2014.

Reichert, A. and Sussmann, R.: The Zugspitze radiative closure experiment for quantifying water vapor absorption over the terrestrial and solar infrared - Part 3: Quantification of the mid- and near-infrared water vapor continuum in the 2500 to $7800 \mathrm{~cm}^{-1}$ spectral range under atmospheric conditions, Atmos. Chem. Phys., 16, 11671-11686, doi:10.5194/acp-16-11671-2016, 2016.

Reichert, A., Rettinger, M., and Sussmann, R.: The Zugspitze radiative closure experiment for quantifying water vapor absorption over the terrestrial and solar infrared - Part 2: Accurate calibration of high spectral-resolution infrared measurements of surface solar radiation, Atmos. Meas. Tech., 9, 4673-4686, doi:10.5194/amt-9-4673-2016, 2016. 
Rose, T., Crewell, S., Löhnert, U., and Simmer, C.: A network suitable microwave radiometer for operational monitoring of the cloudy atmosphere, Atmos. Res., 75, 183-200, doi:10.1016/j.atmosres.2004.12.005, 2005.

Rothman, L. S., Gordon, I. E., Barbe, A., Benner, D. C., Bernath, P. F., Birk, M., Boudon, V., Brown, L. R., Campargue, A., Champion, J.-P., Chance, K., Coudert, L. H., Danaj, V., Devi, V. M., Fally, S., Flaud, J.-M., Gamache, R. R., Goldmanm, A., Jacquemart, D., Kleiner, I., Lacome, N., Lafferty, W. J., Mandin, J.-Y., Massie, S. T., Mikhailenko, S. N., Miller, C. E., Moazzen-Ahmadi, N., Naumenko, O. V., Nikitin, A. V., Orphal, J., Perevalov, V. I., Perrin, A., Predoi-Cross, A., Rinsland, C. P., Rotger, M., Šimečková, M., Smith, M. A. H., Sung, K., Tashkun, S. A., Tennyson, J., Toth, R. A., Vandaele, A. C., and Vander Auwera, J.: The HITRAN 2008 molecular spectroscopic database, J. Quant. Spectrosc. Ra., 110, 533-572, doi:10.1016/j.jqsrt.2009.02.013, 2009.

Rowe, P. M. and Walden, V. P.: Improved measurements of the foreign-broadened continuum of water vapor in the $6.3 \mu \mathrm{m}$ band at $-30^{\circ} \mathrm{C}$, Appl. Optics, 48, 1358-1365, doi:10.1364/AO.48.001358, 2009.

Rowe, P. M., Walden, V. P., and Warren, S. G.: Measurements of the foreign-broadened continuum of water vapor in the $6.3 \mu \mathrm{m}$ band at $-30^{\circ} \mathrm{C}$, Appl. Optics, 45, 4366-4382, doi:10.1364/AO.45.004366, 2006.

Schneider, M., Barthlott, S., Hase, F., González, Y., Yoshimura, K., García, O. E., Sepúlveda, E., Gomez-Pelaez, A., Gisi, M., Kohlhepp, R., Dohe, S., Blumenstock, T., Wiegele, A., Christner, E., Strong, K., Weaver, D., Palm, M., Deutscher, N. M., Warneke, T., Notholt, J., Lejeune, B., Demoulin, P., Jones, N., Griffith, D. W. T., Smale, D., and Robinson, J.: Ground-based remote sensing of tropospheric water vapour isotopologues within the project MUSICA, Atmos. Meas. Tech., 5, 3007-3027, doi:10.5194/amt5-3007-2012, 2012.

Schneider, M., Wiegele, A., Barthlott, S., González, Y., Christner, E., Dyroff, C., García, O. E., Hase, F., Blumenstock, T., Sepúlveda, E., Mengistu Tsidu, G., Takele Kenea, S., Rodríguez, S., and Andrey, J.: Accomplishments of the MUSICA project to provide accurate, long-term, global and high-resolution observations of tropospheric $\left\{\mathrm{H}_{2} \mathrm{O}, \delta \mathrm{D}\right\}$ pairs - a review, Atmos. Meas. Tech., 9, 2845-2875, doi:10.5194/amt-9-2845-2016, 2016.

Serio, C., Masiello, G., Esposito, F., Di Girolamo, P., Di Iorio, T., Palchetti, L., Bianchini, G., Muscari, G., Pavese, G., Rizzi, R., Carli, B., and Cuomo, V.: Retrieval of foreign-broadened water vapor continuum coefficients from emitted spectral radiance in the $\mathrm{H}_{2} \mathrm{O}$ rotational band from 240 to $590 \mathrm{~cm}^{-1}$, Opt. Express, 16, 15816-15833, doi:10.1364/OE.16.015816, 2008.

Shine, K. P., Ptashnik, I. V., and Rädel, G.: The Water Vapour Continuum: Brief History and Recent Developments, Surv. Geophys., 33, 535-555, doi:10.1007/s10712-011-9170-y, 2012.

Sierk, B., Solomon, S., Daniel, J. S., Portmann, R. W., Gutman, S. I., Langford, A. O., Eubank, C. S., Dutton, E. G., and Holub, K. H.: Field measurements of water vapor continuum absorption in the visible and near-infrared, J. Geophys. Res., 109, D08307, doi:10.1029/2003JD003586, 2004.

Simmer, C.: Satellitenfernerkundung hydrologischer Parameter der Atmosphäre mit Mikrowellen, 314 pp., Dr. Kovac, Hamburg, 1994.
Staehelin, J., Kerr, J., Evans, R., and Vanicek, K.: Comparison of total ozone measurements of Dobson and Brewer spectrophotometers and recommended transfer functions, WMO TD No. 1147, available at: http://library.wmo.int/pmb_ged/wmo-td_1147.pdf (last access: 15 September 2016), 2003.

Sussmann, R. and Borsdorff, T.: Technical Note: Interference errors in infrared remote sounding of the atmosphere, Atmos. Chem. Phys., 7, 3537-3557, doi:10.5194/acp-7-3537-2007, 2007.

Sussmann, R. and Camy-Peyret, C.: Ground-Truthing Center Zugspitze, Germany for AIRS/IASI Validation, Phase I Report, EUMETSAT, 18 pp., available at: http://www.imk-ifu.kit.edu/ downloads/institute/AIRSVAL_Phase_I_Report.pdf (last access: 15 September 2015), 2002.

Sussmann, R. and Camy-Peyret, C.: Ground-Truthing Center Zugspitze, Germany for AIRS/IASI Validation, Phase II Report, EUMETSAT, 15 pp., available at: http://www.imk-ifu.kit.edu/ downloads/institute/AIRSVAL_Phase_II_Report.pdf (last access: 15 September 2015), 2003.

Sussmann, R. and Schäfer, K.: Infrared spectroscopy of tropospheric trace gases: combined analysis of horizontal and vertical column abundances, Appl. Optics, 36, 735-741, doi:10.1364/AO.36.000735, 1997.

Sussmann, R., Borsdorff, T., Rettinger, M., Camy-Peyret, C., Demoulin, P., Duchatelet, P., Mahieu, E., and Servais, C.: Technical Note: Harmonized retrieval of column-integrated atmospheric water vapor from the FTIR network - first examples for longterm records and station trends, Atmos. Chem. Phys., 9, 89878999, doi:10.5194/acp-9-8987-2009, 2009.

Sussmann, R., Forster, F., Rettinger, M., and Jones, N.: Strategy for high-accuracy-and-precision retrieval of atmospheric methane from the mid-infrared FTIR network, Atmos. Meas. Tech., 4, 1943-1964, doi:10.5194/amt-4-1943-2011, 2011.

Sussmann, R., Forster, F., Rettinger, M., and Bousquet, P.: Renewed methane increase for five years (2007-2011) observed by solar FTIR spectrometry, Atmos. Chem. Phys., 12, 4885-4891, doi:10.5194/acp-12-4885-2012, 2012.

Tobin, D., Best, F., Brown, P., Clough, S., Dedecker, R., Ellingson, R., Garcia, R., Howell, H., Knuteson, R., Mlawer, E., Revercomb, H., Short, J., van Delst, P., and Walden, V.: Downwelling spectral radiance observations at the SHEBA ice station: Water vapor continuum measurements from 17 to $26 \mu \mathrm{m}$, J. Geophys. Res., 104, 2081-2092, doi:10.1029/1998JD200057, 1999.

Tobin, D. C., Revercomb, H. E., Knuteson, R. O., Lesht, B. M, Strow, L. L., Hannon, S. E., Feltz, W. F., Moy, L. A., Fetzer, E. J., and Cress, T. S.: Atmospheric Radiation Measurement site atmospheric state best estimates for Atmospheric Infrared Sounder temperature and water vapor retrieval validation, J. Geophys. Res., 111, D09S14, doi:10.1029/2005JD006103, 2006.

Toledano, C., Wiegner, M., Garhammer, M., Seefeldner, M., Gasteiger, J., Müller, D., and Koepke, P.: Spectral aerosol optical depth characterization of desert dust during SAMUM 2006, Tellus B, 61, 216-228, doi:10.1111/j.1600-0889.2008.00382.x, 2009.

Turner, D. D. and Mlawer, E. J.: Radiative heating in underexplored bands campaigns (RHUBC), B. Am. Meteorol. Soc., 91, 911923, doi:10.1175/2010BAMS2904.1, 2010.

Turner, D. D., Tobin, D. C., Clough, S. A., Brown, P. D., Ellingson, R. G., Mlawer, E. J., Knuteson, R. O., Revercomb, H. E., Shippert, T. R., Smith, W. L., and Shephard, M. W.: The QME AERI 
LBLRTM: A Closure Experiment for Downwelling High Spectral Resolution Infrared Radiance, J. Atmos. Sci., 61, 2657-2675, doi:10.1175/JAS3300.1, 2004.

Turner, D. D., Knuteson, R. O., and Revercomb, H.: Noise reduction of atmospheric emitted radiance interferometer (AERI) observations using principal component analysis, J. Atmos. Ocean. Tech., 23, 1223-1238, doi:10.1175/JTECH1906.1, 2006.

Turner, D. D., Merrelli, A., Vimont, D., and Mlawer, E. J.: Impact of modifying the longwave water vapor continuum absorption model on community Earth system model simulations, J. Geophys. Res., 117, D04106, doi:10.1029/2011JD016440, 2012a.

Turner, D. D., Mlawer, E. J., Bianchini, G., Cadeddu, M. P., Crewell, S., Delamere, J. S., Knuteson, R. O., Maschwitz, G., Mlynzcak, M., Paine, S., Palchetti, L., and Tobin, D. C.: Ground-based high spectral resolution observations of the entire terrestrial spectrum under extremely dry conditions, Geophys. Res. Lett., 39, L10801, doi:10.1029/2012GL051542, 2012b.
Vogelmann, H., Sussmann, R., Trickl, T., and Borsdorff, T.: Intercomparison of atmospheric water vapor soundings from the differential absorption lidar (DIAL) and the solar FTIR system on Mt. Zugspitze, Atmos. Meas. Tech., 4, 835-841, doi:10.5194/amt-4-835-2011, 2011.

Vogelmann, H., Sussmann, R., Trickl, T., and Reichert, A.: Spatiotemporal variability of water vapor investigated using lidar and FTIR vertical soundings above the Zugspitze, Atmos. Chem. Phys., 15, 3135-3148, doi:10.5194/acp-15-3135-2015, 2015. 